\title{
INVESTIGATION OF THE MELTING PROCESS OF POLYETHYLENE GLYCOL 1500 (PEG 1500) IN A RECTAGULAR ENCLOSURE
}

F A Hamad, Emenike Egelle, Kieron Cummings, Paul Russell

School of Science and Engineering

Teesside University

Southfield Road, Middlesbrough

TS1 3BA, United Kingdom 


\section{Abstract}

The melting process of polyethylene glycol 1500 (PEG 1500) adjacent to a hot vertical wall in a rectangular enclosure is investigated experimentally. Polyethylene glycol 1500 was selected because its melting temperature is $>44^{\circ} \mathrm{C}$ making it a suitable candidate as lagging material to prevent wax deposition and hydrate formation in subsea oil pipelines. A new apparatus cell consisting of a rectangular cell $200 \times 200 \times 180 \mathrm{~mm}$ split equally into three chambers by two, $2 \mathrm{~mm}$ thick, aluminium plates was constructed. Each end chamber was supplied with hot and cold water respectively. The centre chamber was filled with PEG1500. Thermocouples and an infrared camera were used to measure the temperature at different locations inside and on the surface of the phase change material (PCM). The temperature contours, percentage (\%) of melting and the melt front evolution are presented for various operating conditions. A dye tracer solution was used to show the natural circulation of the $\mathrm{PCM}$ as it melted. Results indicate that during the initial stage of melting heat conduction is the dominating mode of heat transfer, followed by transition from conduction to convection regime and convection dominating heat transfer regime. The results show a strong correlation between the hot wall temperature and the fraction melt as it control the convection heat transfer. In contrast, the results also show that cold wall temperature have insignificant effect on fraction of PCM melt with the time for constant hot wall temperature and the melt rate has a same characteristic shape for all cold wall temperatures used in this study. A dye tracer study shows the natural circulation in the liquid zone, confirm the presence of the strongest convection at the solid-liquid interface and reveal the velocity profile/current direction. An approximate time of six minutes was recorded for the circulation of the solution round the enclosure giving approximate velocity of $0.00117 \mathrm{~m} / \mathrm{s}$.

Keywords: Thermal energy storage; melting of Peg 1500; phase change material; latent heat; Dye tracer 


\section{Table of content}

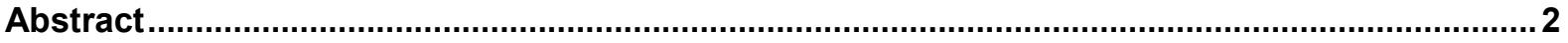

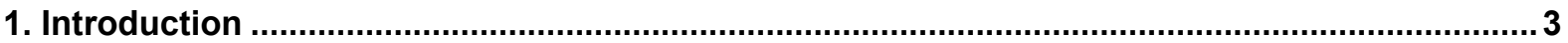

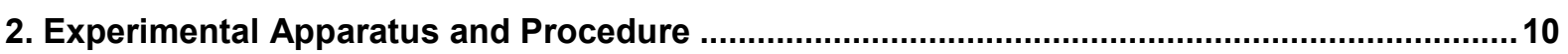

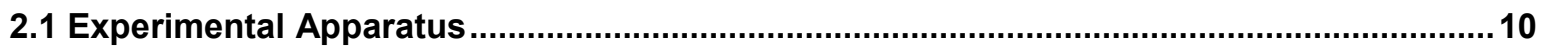

2.2 Experimental Procedure .................................................................................................. 12

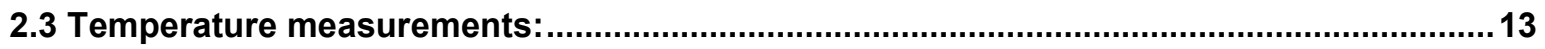

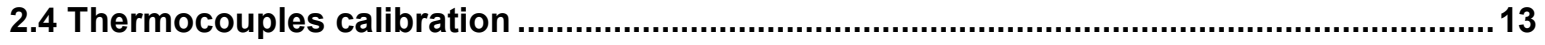

2.5 Calibration of infrared camera .................................................................................... 14

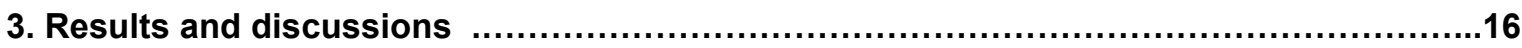

3.1 Verification of 2-dimensional heat transfer ............................................................. 17

3.2 Contours of temperatures measured by infrared camera on the side wall of PCM cavity 18 3.3 Visual Observation and Data Deduction from the melting of PEG 1500 :Melt Profile .......20

3.4 Effect of hot wall temperature on melting rate ...............................................................29

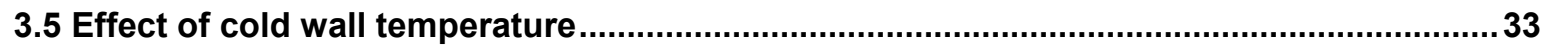

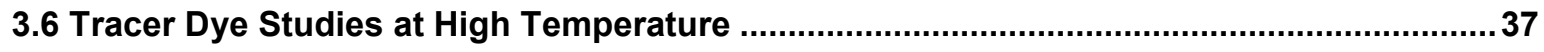

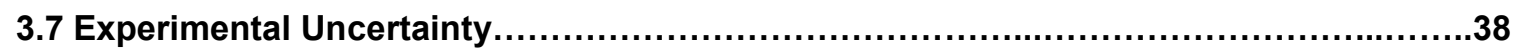

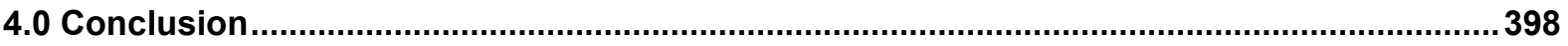

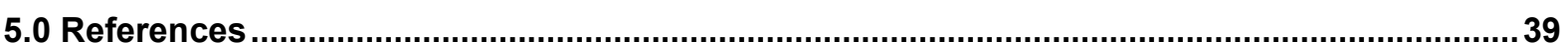

\section{Nomenclature}

$\mathrm{Fr}_{\mathrm{r}} \quad$ fraction melted

Mf melted area

t time

At total cross sectional area of the PCM perpendicular to $y$ axis

$\mathrm{A}_{\mathrm{h}} \quad$ total cross sectional area of the PCM perpendicular to $\mathrm{x}$ axis

$\mathrm{K} \quad$ Constant in eq. (2)

A Constant in eq. (2)

$\mathrm{h}$ heat transfer coefficient

$\Delta \mathrm{T}$ temperature difference through the liquid -solid interface

$\Delta \mathrm{T}_{1}$ temperature difference through the melted zone of PCM

$\Delta \mathrm{T}_{2}$ temperature difference through the solid zone of PCM

$\Delta \mathrm{X}_{1} \quad$ thickness of the melted zone of PCM

$\Delta \mathrm{X}_{2} \quad$ thickness of the solid zone of PCM

$\mathrm{T}_{\mathrm{c}}$ temperature of the cold wall

$\mathrm{T}_{\mathrm{h}}$ temperature of the hot wall 
Ra Rayleigh number, $g \beta\left(T_{w}-T_{m}\right) H^{3} / \alpha v$

Ste Stephan number, $c\left(T_{w}-T_{m}\right) / h_{s l}$

Fo Fourier number Fo $=\alpha t / L^{2}$

C specific heat at constant pressure

Tm melting temperature

$\mathrm{h}_{\mathrm{sl}} \quad$ latent heat

$\mathrm{H}$ height of rectangular enclosure

Q Heat transfer to PCM

K1 thermal conductivity of liquid phase

K2 thermal conductivity of solid phase

$\mathrm{L}$ length of rectangular enclosure

a thermal diffusivity

$\beta \quad$ volumetric expansion coefficient

g gravitational constant

V kinematic viscosity

$X, Y$ Cartesian coordinates of the melt front

$X \quad$ axis perpendicular to melt front

$Y \quad$ axis parallel to melt front

$Z \quad$ the vertical axis 


\section{Introduction}

Phase change materials (PCMs) are of considerable interest for thermal energy storage simply because of their high thermal energy densities per unit volume and a fixed temperature where the phase change occurs. The most common example of this is water/steam used widely throughout the process industries' as the heat transfer fluid of first choice. Interest in solid-liquid PCM has grown recently leading to a number of notable applications: electronic devices (Fok et al. 2010; Wang et al. 2010; Tan and Tso, 2004), solar thermal systems (Alkilani et al. 2011; Khalifa et al. 2013), buildings (Stritih and Butala, 2010; Tay et al. 2012), refrigeration (Liu et al. 2012), spacecraft's (Kim et al. 2013; Swanson and Birur, 2003), heat recovery (Gu et al. 2004), smart textiles (Mondal, 2008; Sarier and Onder, 2012) and desalination (Arunkumar et al. 2013).

This growth of interest in PCM materials has stimulated a need for a better understanding of the heat transfer processes, which take place during phase transformations. Research carried out to date on these materials has concentrated on developing an understanding of the heat transfer characteristics of the PCM, specifically the effect of natural convection on solid-liquid interface transition and different techniques to improve the heat transfer between PCM and that of the heat transfer fluid (HTF).

Many organic and inorganic PCM materials are used as thermal-storage media but no single material can satisfy all requirements for all applications. This has led to a significant amount of research to develop an adequate system design to overcome the limitations of the specific PCM used in each application. For example, metallic fins were used to improve the thermal conductivity for energy storage devices. A summary recent published work on inorganic and organic PCM materials is presented below to highlight their uses and limitations.

Inorganic PCMs: Inorganic materials include salt hydrates and metals. Salt hydrates may be regarded as alloys of inorganic salts and water forming a crystalline solid. Salt hydrates have been extensively studied for their use in latent heat thermal energy storage systems (Kenisarin (2010)). The advantage and disadvantage properties associated with inorganic PCM have been discussed by Chiu (2011) and 
Sharma (2009). The main advantages of these materials are: high latent heat of fusion per unit volume, high thermal conductivity (almost double of the organic material) and small volume changes on melting.

The main works involving metals include: Gau and Viskanta (1985) who examined gallium $(\operatorname{Pr} \approx 0.021)$ in a rectangular enclosure. They monitored the effect of natural convection on the solid-liquid interface. Further investigative work by Gau and Viskanta (1986) studied the influence of natural convection on the melting of gallium on a vertical wall. They discovered that in spite of the high thermal conductivity of the metallic PCM (gallium) which can increase the role of conduction heat transfer, the interface evolution shape and melting rate was controlled by laminar buoyancy driven natural convection. Wolff and Viskanta (1988) also studied the melting of a pure metal (tin, $\operatorname{Pr} \approx 0.009$ ) on a vertical wall. They studied the solid-liquid interface position by the evaluation of the effect of convection currents and the temperature field during the solidification of superheated tin $(\operatorname{Pr} \approx 0.009)$ in a rectangular cavity using a probe technique to detect the location of the solid/liquid interface. Their results revealed that the shape and motion of the solid-liquid interface was not greatly affected by natural convection in the liquid metal during the phase change. This change in behaviour when compared with the work of Gau and Viskanta (1985, 1986 ) is thought to be due to the high thermal conductivity of tin which has led to an order of magnitude drop in Prandtl number and a corresponding switch between convection and conduction as the dominant heat transfer mechanism for the two studies.

The main work on metal salts was conducted by Kenisarin (2010) who gave a detailed review on the developments of high-temperature phase change materials for the range of temperatures from 120 to $1000{ }^{\circ} \mathrm{C}$. Kenisarin (2010) considered a significant quantity of mixes and compositions based on fluorides, chlorides, hydroxides, nitrates, carbonates, vanadates, molybdates and other salts, and metal alloys. Thermophysical properties of potential heat storage salt compositions and metal alloys were presented alongside compatibility of heat storage materials (HSM) and constructional materials. Data on long-term characteristics of some HSMs in the course of repeated cycles of fusion and solidification were analysed and other 
problems that need to be solved for creation of commercial high-temperature heat storage devices using phase change materials were discussed.

Organic PCMs: The main organic PCMs are paraffins, fatty acids and the polyethylene glycol (PEG). They have been used widely due to their availability in a large temperature range. Some of the beneficial and unfavourable characteristics of organics are discussed by (Gabriela, 2012) and (Ravikumar \& Srinivason, 2008). They have high latent heat, low thermal conductivity that leads to very long freezemelt cycles. These factors that make them most appropriate for present research.

The main works in this area are: Ho and Viskanta (1984) investigated the melting of n-octadecane from an isothermal vertical wall of a rectangular cavity. The results clearly showed that, except in the very early stages of melting, the rates of melting and of heat transfer controlled by the buoyancy-driven convection in the liquid. Benard et al. (1985) studied the melting process of pure $n$ - octadecane. They concluded that the melting process could be considered a two-stage process based on the melt front location with respect to the cold wall. Initially heat transfer is controlled by conduction in stage one. Once sufficient material is melted, the process becomes convection controlled in stage 2 . These findings confirmed the observations of Ho and Viskanta (1984). Webb and Viskanta (1986) investigated the heat transfer of n-octadecane melting in an inclined rectangular enclosure. Enclosure inclination was used to establish three-dimensional natural convective motion, which intensifies as the inclination angle from the vertical, is increased. The three dimensionality of the flow field results in non-uniform melting of the solid zone. Ahmad et al (2006) use PEG 600 to fill the PVC panel to overcome the conductivity problem due to the presence of air because of its low cost and its availability. They found that the PVC panels filled with PEG 600 showed properties compatible with their objective of a light envelope having a high heat capacity storage. Reliability tests have been realised and no deterioration of properties was noted after more than 400 thermal cycles. Assis et al. (2007) performed a numerical and experimental study on melting paraffin wax RT27 (Rubitherm $\mathrm{GmbH}$ ) in a spherical geometry placed in a constant temperature water bath. With the aid of a digital camera, they recorded melting images at various stages of the melting process and used the photographs to calculate the transient melt fraction. They observed that such melting 
in a spherical shell is accomplished by sinking of the solid in the liquid as well as close contact heat transfer between the shell and the solid PCM. Yanxia et al (2007) reported experimental investigation of the melting process of ethanolamine-water binary mixture used as PCM in a rectangular enclosure with a heated vertical wall. The liquid-solid interfaces were captured and the instantaneous liquid fraction was presented. The effect of natural convection was studied in terms of the molten fraction and the shape of the solid-liquid interface. The correlations of molten fraction and time-averaged Nusselt number were obtained so that the duration of the melting process could be predicted. The results indicated that natural convection enhances the rate of melting compared with the pure conduction model and that pure conduction only occurs during the initial stage of melting. Shokouhmand and Kamkari (2013) performed an experimental investigation on melting heat transfer characteristics of lauric acid in a rectangular enclosure. Lauric acid (melting point $\left.42^{\circ} \mathrm{C}\right)$ was chosen because it has a very high Prandtl number $(\operatorname{Pr} \approx 100)$ and is therefore more suited to heat storage applications than n-octadecane. They studied the interface evolution and temperature distribution during the melting progression. They reported on the role of natural convection heat transfer during the different stages of the melt front evolution. They concluded that during the initial stage of melting, heat conduction was the dominant mode of heat transfer, followed by transition from conduction to convection regime and finally convection dominated heat transfer. However, approaching the end of the melting process, bulk temperature of the liquid PCM increases and stratified temperature field appear in the upper part of the enclosure, which reveal depression of the convection currents. Kamkari et al (2014) investigated the dynamic thermal behaviour of phase change material (PCM) melting in a rectangular enclosure at various inclination angles using the Lauric acid as a PCM. Experiments were performed with hot wall temperatures of $53,62.5$ and $70.1{ }^{\circ} \mathrm{C}$ for different inclination angles of $0^{\circ}, 45^{\circ}$ and $87^{\circ}$. The results showed that the enclosure inclination has a significant effect on the formation of natural convection currents and consequently on the heat transfer rate and melting time of the PCM. As the inclination angle is decreased from $87^{\circ}$ to $0^{\circ}$, the convection currents in the enclosure increases and chaotic flow structures appear. It was found that the heat transfer enhancement ratio for the horizontal enclosure is more than twice that of the vertical enclosure. Kamkari and Shokouhm (2014) performed an experimental investigation using Lauric acid as a PCM in a transparent rectangular 
enclosure with and without horizontal partial fins. Experimental data were used to calculate melt fractions, heat transfer rates and Nusselt numbers during the melting process. Experimental results indicated that increasing the number of fins decreased the melting time and increased the total heat transfer rate while the surfaceaveraged Nusselt number reduced. Melting enhancement ratios decreased with time after reaching some maximum values indicating that partial fins are more beneficial during the initial time of the melting.

The work reported above concentrates on the liquid phase heat transfer processes in the melted PCM. The main problem with application of PCMs to heat storage, if the liquid phase heat transfer can be enhanced through convection, is the low thermal conductivity of the solid phase. The remaining extant work on these materials has centred on improving conduction transfer in the solid phase, which is often the ratelimiting step. Enhancement techniques carried out to increase the thermal performance of PCMs includes utilization of finned tubes (Tay et al. 2013; Sharifi et al. 2011), placement of high thermal conductivity metals spheres/screens (Velraj et al. 1999; Ettouney et al. 2004), use of embedded heat pipes (Robak et al. 2011), use of carbon fiber brushes (Fukai et al. 2003), use of nanoparticles (Khodadadi and Hosseinizadah, 2007), use of carbon nanotubes (Wang et al. 2010; Tumuluri et al. 2011).

This project aimed to look at the application of PCM (specifically polyethylene glycol waxes) for insulation and temperature control of subsea oil transmission pipelines, where the task is to prevent heat loss rather than promote heat transfer. It therefore has different requirements of a PCM than most latent heat thermal energy storage applications. In this case, a slow heat transfer rate is beneficial. The low thermal conductivity of polyethylene glycol waxes makes them a favourable option, as the main objective is to prolong the heat discharge process.

Only a limited amount of work has been done on polyethylene glycol waxes. Wang et al. (1999) carried out an experimental investigation of the melting process of Polyethylene Glycol 900 (PEG 900) using a rectangular enclosure. The experiment was conducted with the use of a flat-plate heat pipe to establish a uniform wall temperature and at different wall temperatures it revealed the considerable role of 
natural convection on the melt front shape. Unfortunately, this wax is not suitable for this application because it has a low melting temperature of $21-25^{\circ} \mathrm{C}$ which is below that required to prevent hydrate ice formation. Polyethylene glycol 1500 in contrast has not been studied but has a melting point greater than $44{ }^{\circ} \mathrm{C}$ and is therefore suitable for this application.

This paper sets out the findings of an experimental study designed to characterise the melting process and heat transfer mechanisms in the melt phase for polyethylene glycol 1500. The experimental programme comprised the following steps: i) Visual observation, recorded by photography, of the temporal development of the melting process at different differential temperatures; ii) Production of a temperature history of for the PCM block recorded for different imposed differential temperatures using thermocouples for local temperatures within the PCM and an infrared camera for surface temperature measurement; iii) investigation of the influence of hot wall temperature on the melting process; iv) investigation of the influence of cold wall temperature on the melting process; v) investigation of the flow patterns established within the melt phase using dye tracer studies.

\section{Experimental Apparatus and Procedure}

\subsection{Experimental Apparatus}

The apparatus was designed specifically to provide accurate measurements of the instantaneous melt front as well as the temperature distribution within the PCM. Figure 1 shows the schematic diagram of the apparatus used in the investigation.

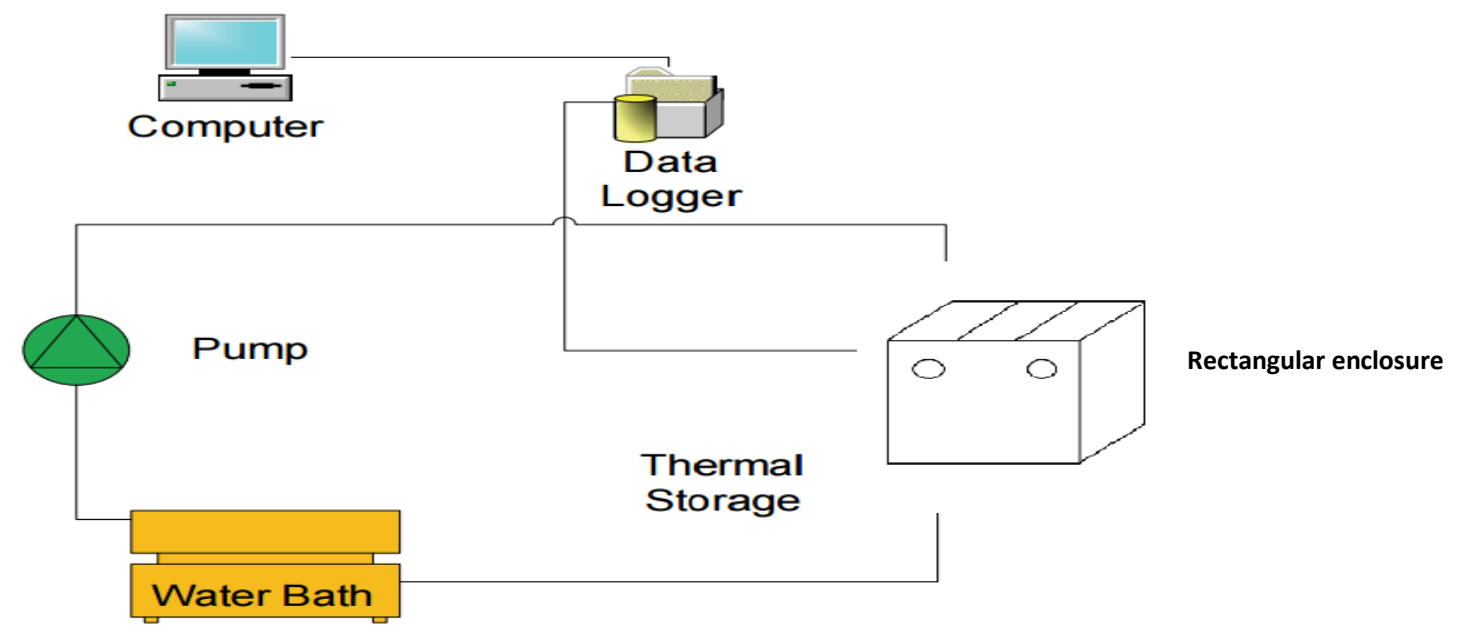

Figure 1. Schematic diagram of the experimental apparatus 
The experimental apparatus consists of the rectangular enclosure, temperature data logger, a circulation pump, a constant temperature hot water bath, a cold-water circulator and an infrared camera. The rectangular enclose is used

The rectangular enclosure was constructed from $6 \mathrm{~mm}$ thick Perspex material with dimensions of $200 \times 200 \times 180 \mathrm{~mm}$. A rectangular transparent geometry has been used by other investigators, notably (Shokouhmand and Kamkari (2013), Wang et al (1999)) for initial detailed study of melting/solidification process due the simplicity of construction and higher accuracy of recording the melting/solidification process through the transparent walls. The Perspex minimises heat losses from the walls (thermal conductivity $\mathrm{k}=0.189 \mathrm{~W} / \mathrm{mK}$ ) whilst allowing observation of the melting process. The rectangular enclosure (henceforth referred to as the vessel) contains two $2 \mathrm{~mm}$ thick, vertical aluminium plates equally spaced along the $200 \mathrm{~mm}$ length of the vessel, that serve to divide the vessel into three equal compartments, $180 \mathrm{~mm}$ high.

The centre compartment contained the PCM and the two outer compartments contained the heating/cooling water respectively. To allow a water supply to pass through each of the outer compartments, a $15 \mathrm{~mm}$ hole was drilled in the base of each compartment at one end and at the top of the opposite wall. Each hole was fitted with a plastic compression fitting to allow connection to the respective heating/cooling supply/drain. The right compartment of the vessel served as the constant heat source and the left one served as the constant cold source.

Eight K-type thermocouples $(0.5 \mathrm{~mm}$ diameter) with an accuracy of $\pm 0.25 \%$ were positioned at specific locations within the PCM as shown in Figure 2. These thermocouples were placed inside the PCM at the hot aluminium wall, the cold aluminium, middle top, middle centre, middle bottom, side top, side centre and side bottom to measure the temperature distribution. The red rectangles in Figure 2 show the two aluminium plates inserted in the rectangular enclosure. The right side of the hot wall (T1) is the hot compartment and the left side of cold wall (T2) is the coldwater compartment. 


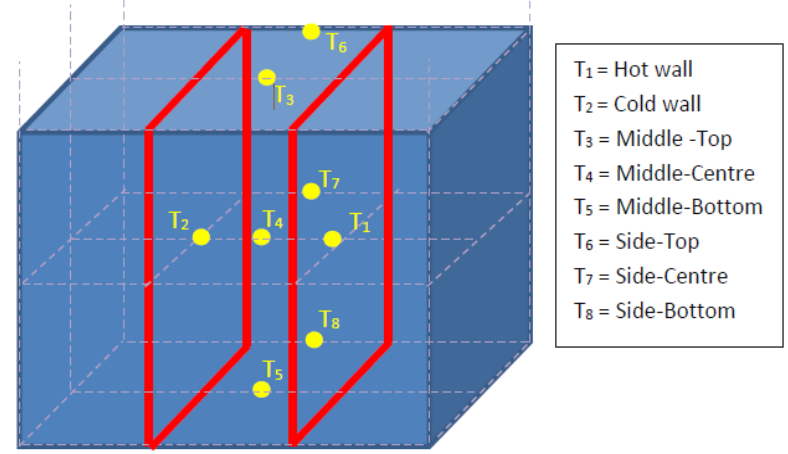

Figure 2. Shows the arrangement of the thermocouple inside the PCM enclosure

All the thermocouples were connected to the computer via a Pico data logger and all temperatures were recorded at 10 s intervals. The hot water was turned off after the desired amount of melting had been achieved and the PCM allowed solidifying with the coolant still running to allow the setting rates to be determined.

\subsection{Experimental Procedure}

Solid PCM, initially in flake form, was melted down, poured into the PCM compartment and left to cool to produce one solid continuous block of PEG 1500. In order to establish a constant initial condition for all the experiments, cold water at $19.6^{\circ} \mathrm{C}$ was circulated through the cooling circulator prior to the start of the experiment to provide a uniform temperature within the solid PCM. Initially the hot water tank was empty. The experiment was started by circulating the hot water from the constant hot water bath through the hot water compartment filling it up and the letting it overflow back to the hot water bath (8 secs to fill to overflow) and establishing a circulation of hot water. The melt front evolution was observed at different set temperatures and a photographic record of these observations was taken.

Two different sets of data were collected. Set 1 used a constant cold water setting of $19.6^{\circ} \mathrm{C}$ and hot water settings of $87^{\circ} \mathrm{C}, 80.1^{\circ} \mathrm{C}, 70.1^{\circ} \mathrm{C}, 62.5^{\circ} \mathrm{C}$, and $53^{\circ} \mathrm{C}$. Set 2 used a constant hot water setting of $80.1^{\circ} \mathrm{C}$ and varied the cold water setting at $35^{\circ} \mathrm{C}$, $19.6^{\circ} \mathrm{C}, 10^{\circ} \mathrm{C}$ and $2^{\circ} \mathrm{C}$. Additional measurements were made for this set using air (temperature $23^{\circ} \mathrm{C}$ ) and ice $0^{\circ} \mathrm{C}$ as the cooling medium. All experiments were repeated to ensure consistency of the results 


\subsection{Temperature measurements:}

The thermocouples at T1 and T2 were glued to the surface of the aluminium walls facing the PCM. T1 was set to measure the temperature of the hot aluminium wall while T2 was set to measure the temperature of the cold aluminium wall. T3, T4, T5 were set to measure the temperature distributions at the mid-top, mid-centre and mid-bottom of the PCM enclosure. T6, T7 and T8 were set to measure the temperature distribution at the side-top, side-centre and side-bottom of the PCM enclosure. Further temperatures were measured at sixteen locations within the PCM compartment on the transparent front wall of the PCM enclosure with an infrared camera. These temperature measurements were used to plot the temperature contours from the PCM enclosure.

The thermocouples $\mathrm{T} 1, \mathrm{~T} 2$ detached from the walls shortly after the PCM melted and thus acted as indicator of the wall temperature rather than measuring the actual wall temperature. Thermocouples T3, T6 were positioned incorrectly and were not used for analysis. The thermocouples T4, T5, T7 and T8 were used for infrared calibration and to provide evidence of the two dimensional heat flow.

\subsection{Thermocouples calibration}

The thermocouples are essentially set in a solid block of material held at a constant temperature and in theory; they should all register the same temperature. A day/night experiment was performed where temperatures were recorded over a twenty-four hour period.

Figure 3 presents the temperatures recorded during the day, the temperature difference between the hot wall and cold wall was $\pm 0.14^{\circ} \mathrm{C}$. The temperature difference between the side top and side bottom was found to be $\pm 0.04^{\circ} \mathrm{C}$. The temperature difference between the middle top and the middle bottom was found to be $\pm 0.14^{\circ} \mathrm{C}$.

A limit of $\pm 0.2^{\circ} \mathrm{C}$ between the consistency of the results for simple two wire K-Type thermocouples is within the expected accuracy of this type of instrument and consistent with data from literature of $\pm 0.2^{\circ} \mathrm{C}$ as given by Burns and Scroger (1989). Alan Tong (2001) shows that the accuracy for K-type thermocouples is $\pm 2.2^{\circ} \mathrm{C}$. 


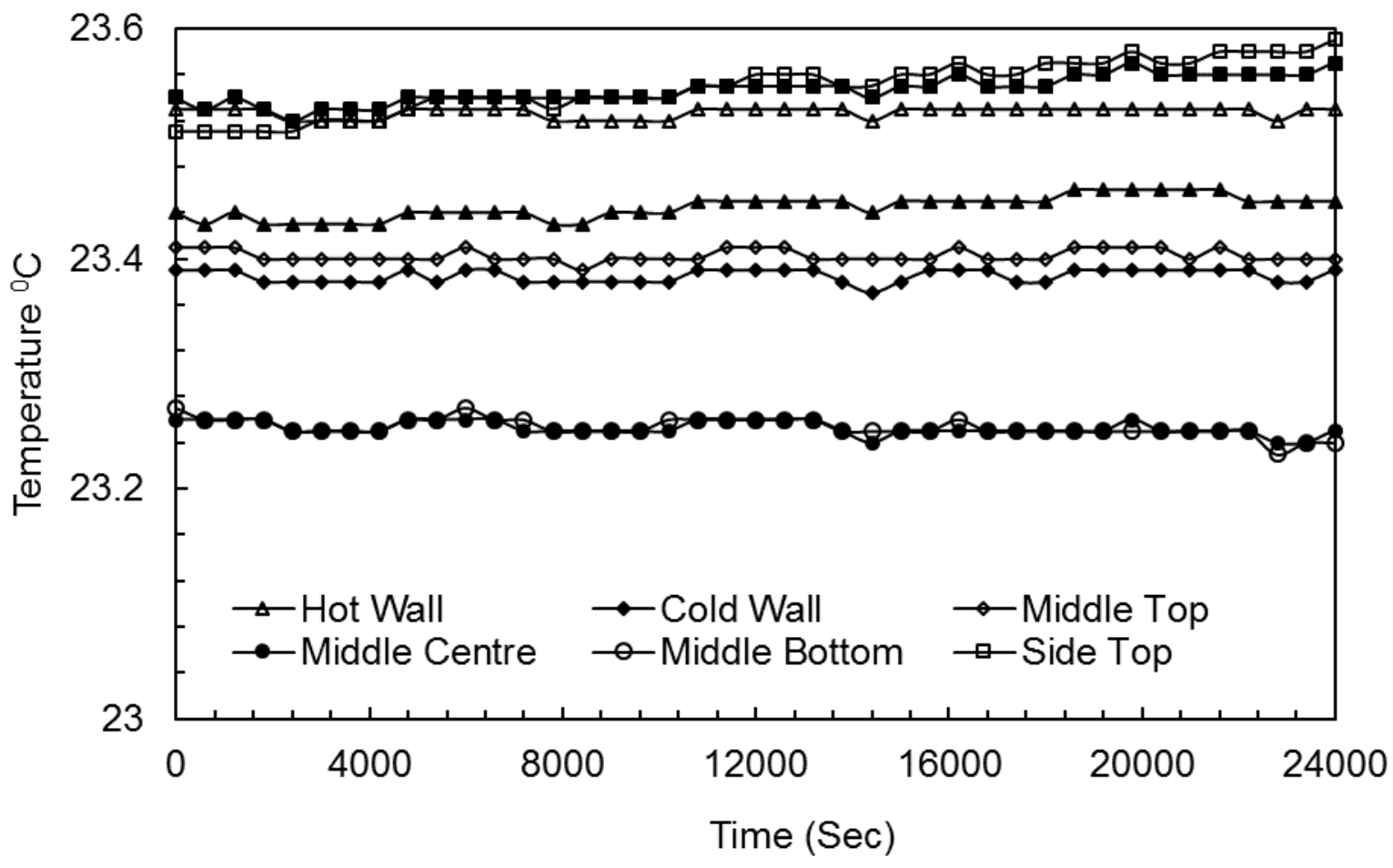

Figure 3. Thermocouples calibration

\subsection{Calibration of infrared camera}

To increase the number of temperature measurements available to plot the temperature contours, an infrared camera focused at different points on the outside front face of the PCM was used to make supplementary temperature measurements. In order to ensure consistency of measurements between the thermocouples and the infrared camera a calibration between the two measurement devices was required. At 10 minute intervals for each experimental measurement made by the thermocouples T7 and T8 glued to the inside surface of the PCM enclosure an infrared camera measurement was made simultaneously to generate some calibration data.

These results for each set of hot water temperature, are presented as plots of temperature against time in Figure $4(a, b, c, d \& e)$.

In all cases, good agreement is seen between the thermocouples and infrared measurements up to about $53^{\circ} \mathrm{C}$ i.e. while the PCM is solid. Above this temperature, a systematic deviation is seen between the indicated temperatures suggesting the molten state of the PCM is affecting the measured temperature of the infrared 
device. This is not to be unexpected as the infrared can now penetrate the PCM affecting its measured response. Given the offset between the two devices is constant for a set hot wall temperature, it is possible to compensate for the offset and correct the infrared readings to given consistent temperature data sets with an accuracy of at least $\pm 1^{\circ} \mathrm{C}$.

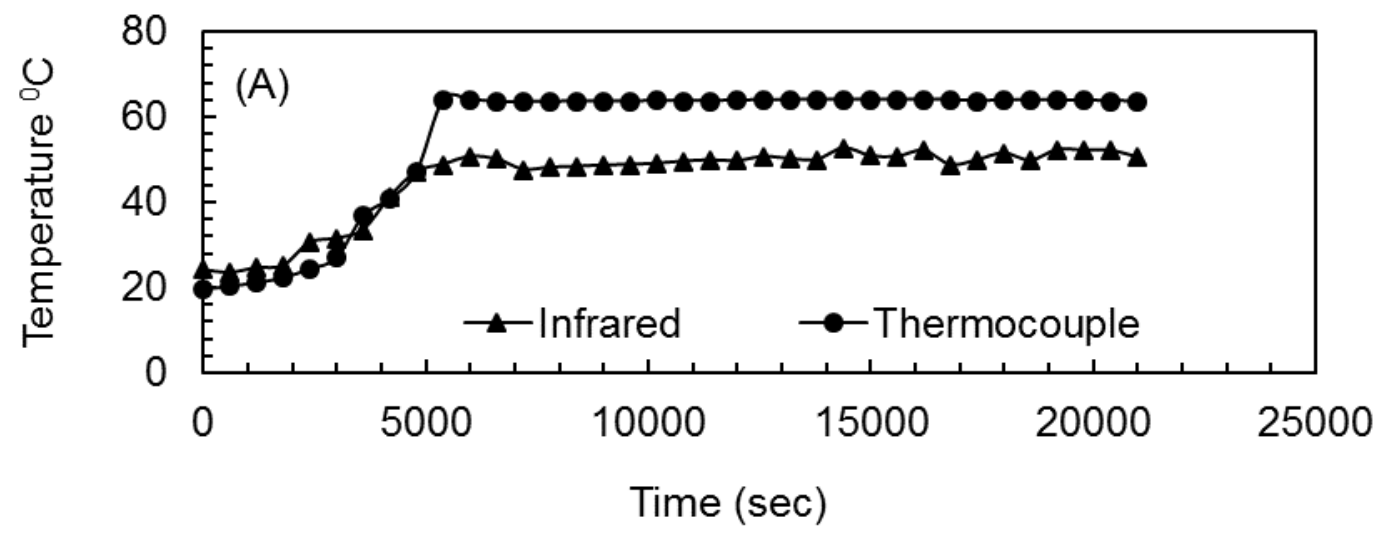

Figure 4a. The infrared and thermocouple measurement recorded at the temperature of $87^{\circ} \mathrm{C}$

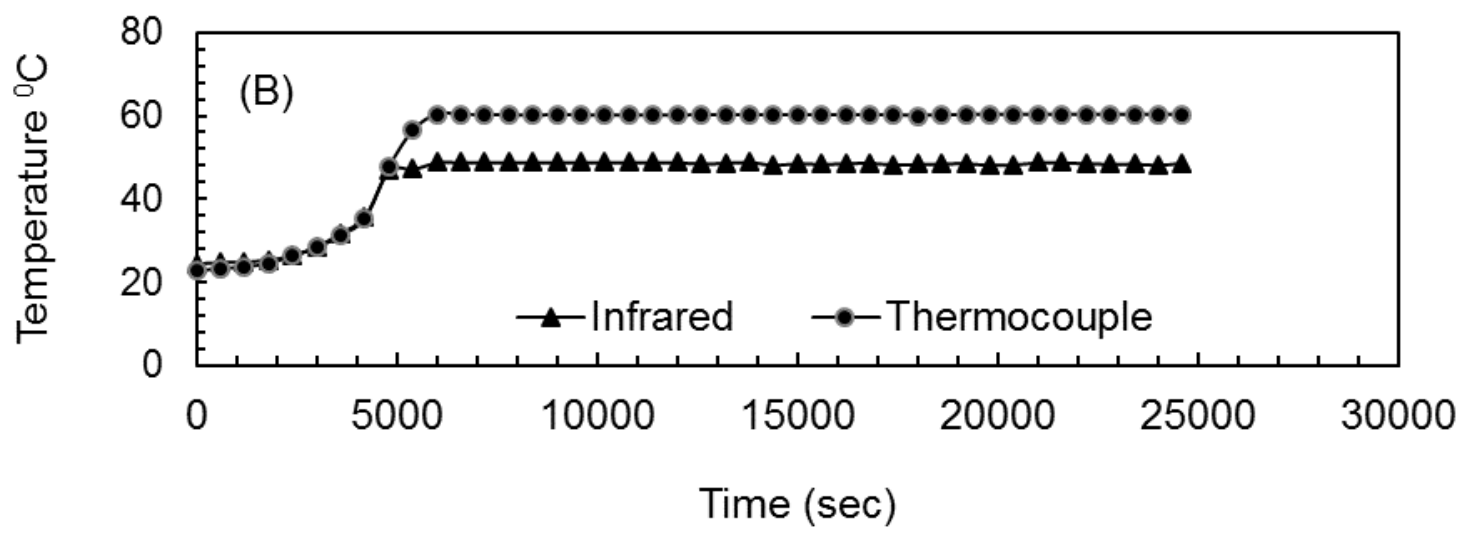

Figure $4 \mathrm{~b}$. The infrared and thermocouple measurement recorded at the temperature of $80.1^{\circ} \mathrm{C}$ 


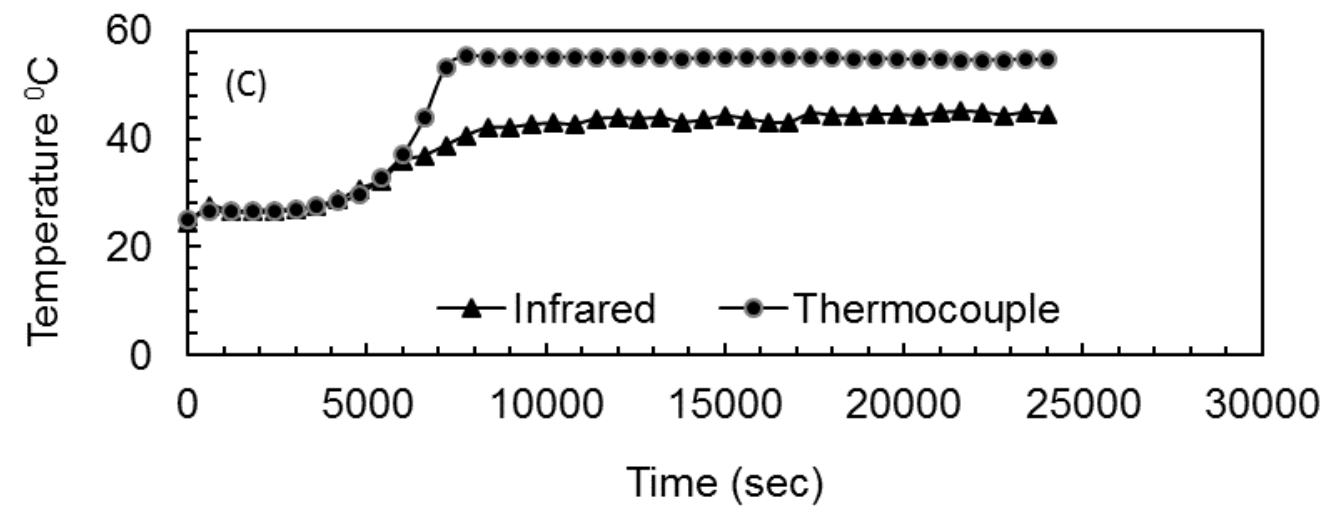

Figure 4c. The infrared and thermocouple measurement recorded at the temperature of $70.1^{\circ} \mathrm{C}$

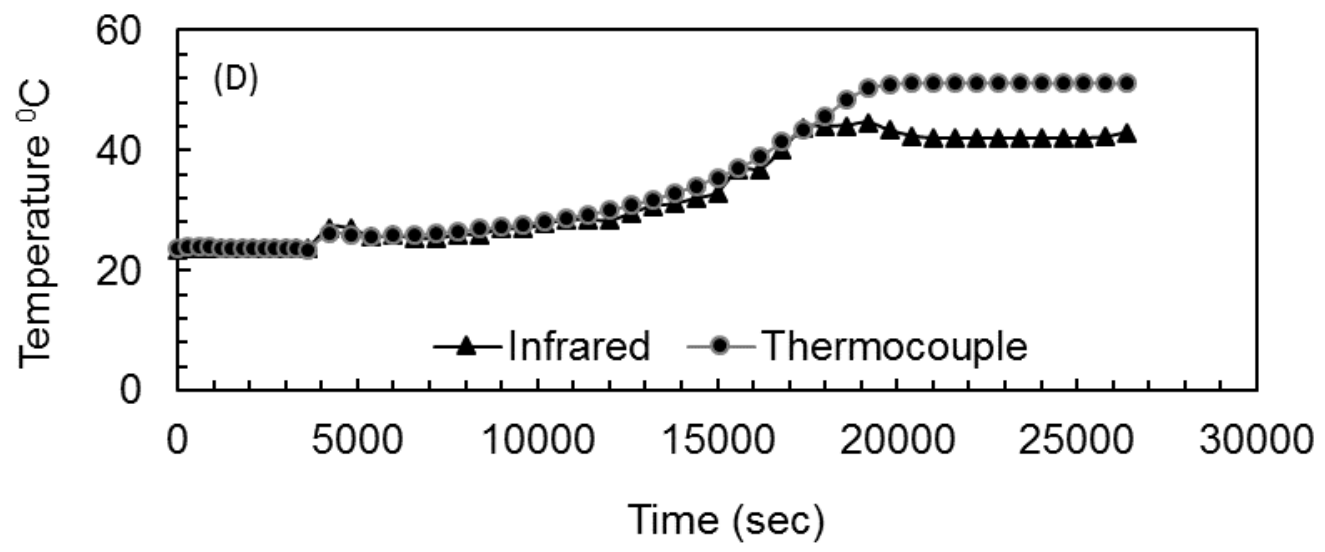

Figure $4 \mathrm{~d}$. The infrared and thermocouple measurement recorded at the temperature of $62.5^{\circ} \mathrm{C}$

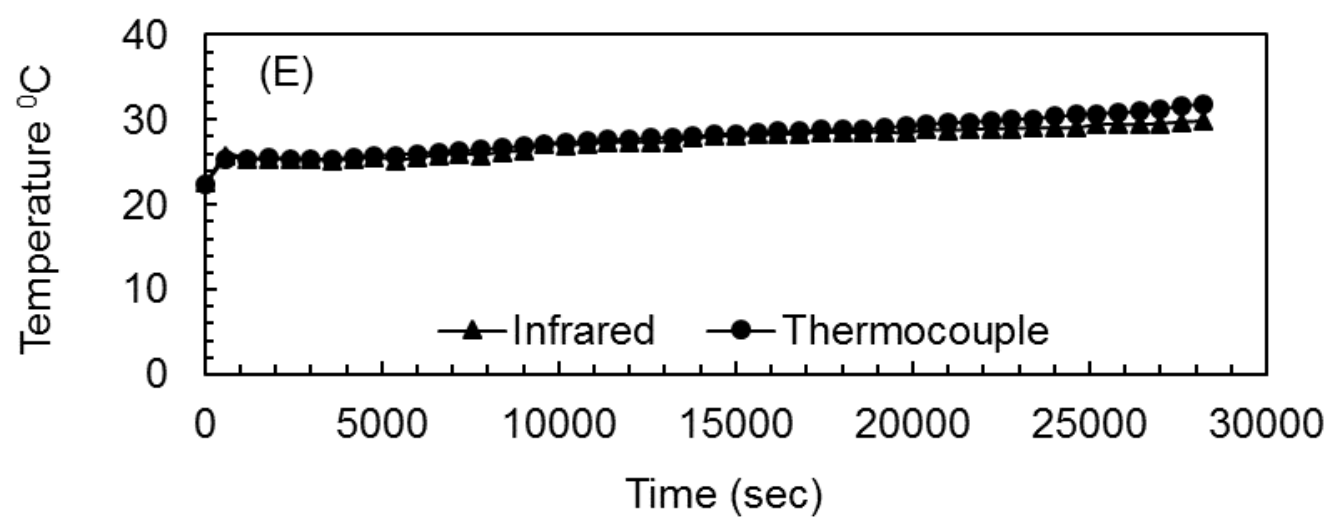

Figure 4e. The infrared and thermocouple measurement recorded at the temperature of $53^{\circ} \mathrm{C}$ 


\section{Results and discussion}

\subsection{Verification of 2-dimensional heat transfer}

To verify that the heat transfer can be considered as two-dimensional, predominantly perpendicular to the aluminium plates with a small amount of vertical circulation due to convection, the temperature distributions parallel to the aluminium plates along the PCM compartment centreline must be investigated. Figure $5 \mathrm{a}$, plots temperatures recorded for the middle centre and sidewall centre positions. Figure $5 \mathrm{~b}$ plots temperatures for middle bottom and side wall bottom positions of the PCM cavity for for dataset 1 The case of $80.1^{\circ} \mathrm{C}$ is taken as an example for discussion. From figure 5 $a \& b$ it is observed that for the first 50 minutes all temperatures are the same and rise at the same rate indicating that measurement points are in solid PCM and that the block temperature is rising evenly. The initial melting phase is almost parallel to the vertical hot wall of the enclosure where heat transfer occurs mainly by conduction due to the large temperature gradient between the hot wall and cold wall temperatures. After 50 minutes, the middle centre and sidewall centre start to increase steeply (Figure 5a) showing the start of PCM melting at these points. After 140 minutes, the middle centre and sidewall centre temperatures stabilise at $62.5^{\circ} \mathrm{C}$ and remain constant till the end of the experiment. This indicates that from this point on a constant temperature gradient is established of $20^{\circ} \mathrm{C}$ between the hot wall and the centre line of the PCM compartment for the centre of the compartment. From Figure $5 \mathrm{~b}$, it can be seen that the side bottom and middle bottom temperatures rise at a linear rate throughout the experiment to a final temperature of $44^{\circ} \mathrm{C}$ indicating they have remained in the solid PCM for the whole duration of the experiment.

The results confirm the heat transfer is predominantly from hot plate to cold plate and that circulation effects are limited to the vertical direction. Little heat transfer is observed across the block parallel to the aluminium plates 


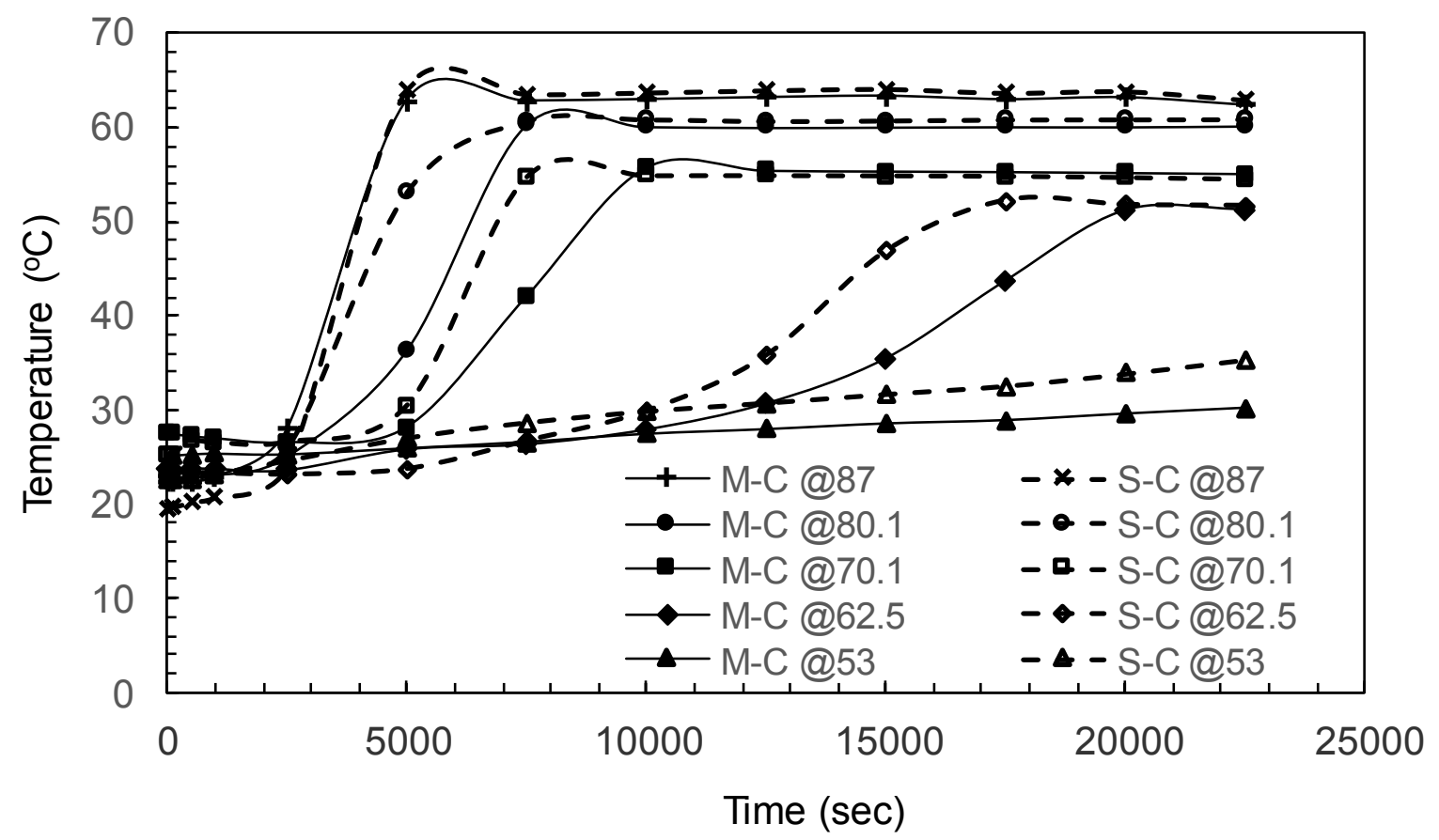

Figure 5a. Comparison of middle centre $(\mathrm{M}-\mathrm{C})$ temperature with side centre $(\mathrm{S}-\mathrm{C})$ temperature for hot wall temperatures of $87,80.1,70.1,62.5$ and $53^{\circ} \mathrm{C}$

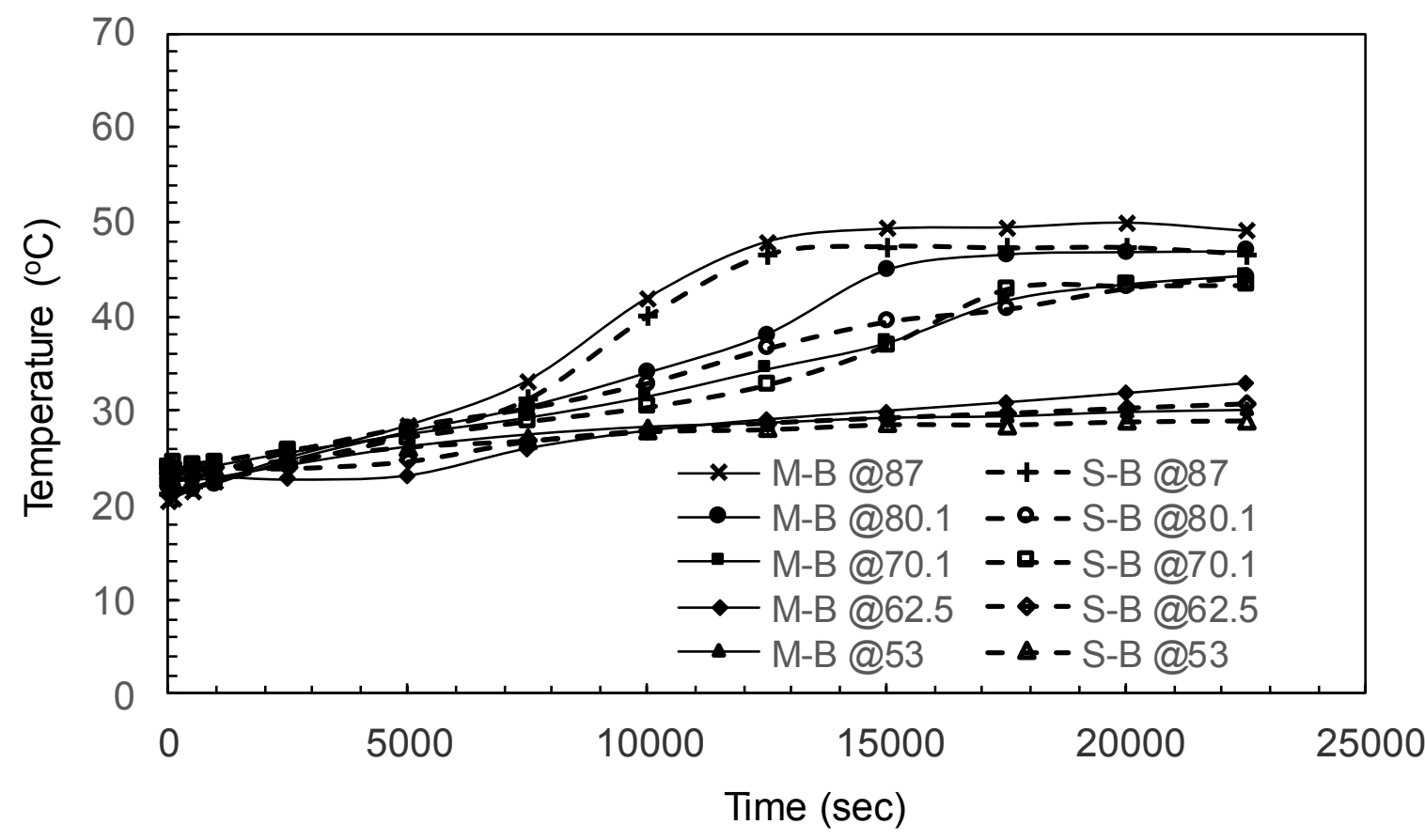

Figure $5 \mathrm{~b}$. Comparison of middle bottom (M-B) temperature with side Bottom (S-B) temperature for hot wall temperatures of $87,80.1,70.1,62.5$ and $53^{\circ} \mathrm{C}$.

\subsection{Contours of temperatures measured by infrared camera on the sidewall of} PCM compartment.

Figure 6, identifies where the readings from the infrared camera were recorded at sixteen different locations (indicated by the numbers) on the PCM compartment wall. 
The temperatures were recorded every ten minutes throughout the experiment and were corrected using the calibration data in section 3.3 to compensate for the distortion caused by the melted polymer.

\begin{tabular}{|c|c|c|c|c|c|}
\hline \multirow{3}{*}{ 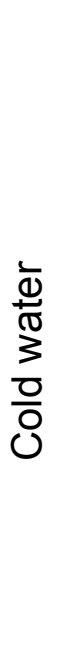 } & $\begin{array}{l}\mathrm{T} 1 \\
\bullet\end{array}$ & $\begin{array}{l}\mathrm{T} 2 \\
\bullet\end{array}$ & $\begin{array}{l}\text { T3 } \\
\bullet\end{array}$ & $\begin{array}{l}\text { T4 } \\
\bullet\end{array}$ & \multirow{3}{*}{ 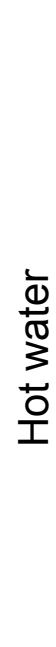 } \\
\hline & $\begin{array}{l}\text { T5 } \\
\bullet \\
\text { T9 } \\
\bullet\end{array}$ & $\begin{array}{l}\text { T10 } \\
\bullet\end{array}$ & $\begin{array}{l}\mathrm{T} 11 \\
\bullet\end{array}$ & $\begin{array}{l}\text { T8 } \\
\bullet\end{array}$ & \\
\hline & $\begin{array}{l}\mathrm{T} 13 \\
\bullet\end{array}$ & $\begin{array}{l}\text { T14 } \\
\bullet\end{array}$ & $\begin{array}{l}\mathrm{T} 15 \\
\bullet\end{array}$ & $\begin{array}{l}\text { T16 } \\
\bullet\end{array}$ & \\
\hline
\end{tabular}

Figure 6. The various locations of the infrared readings recorded at the PCM quadrant section. 

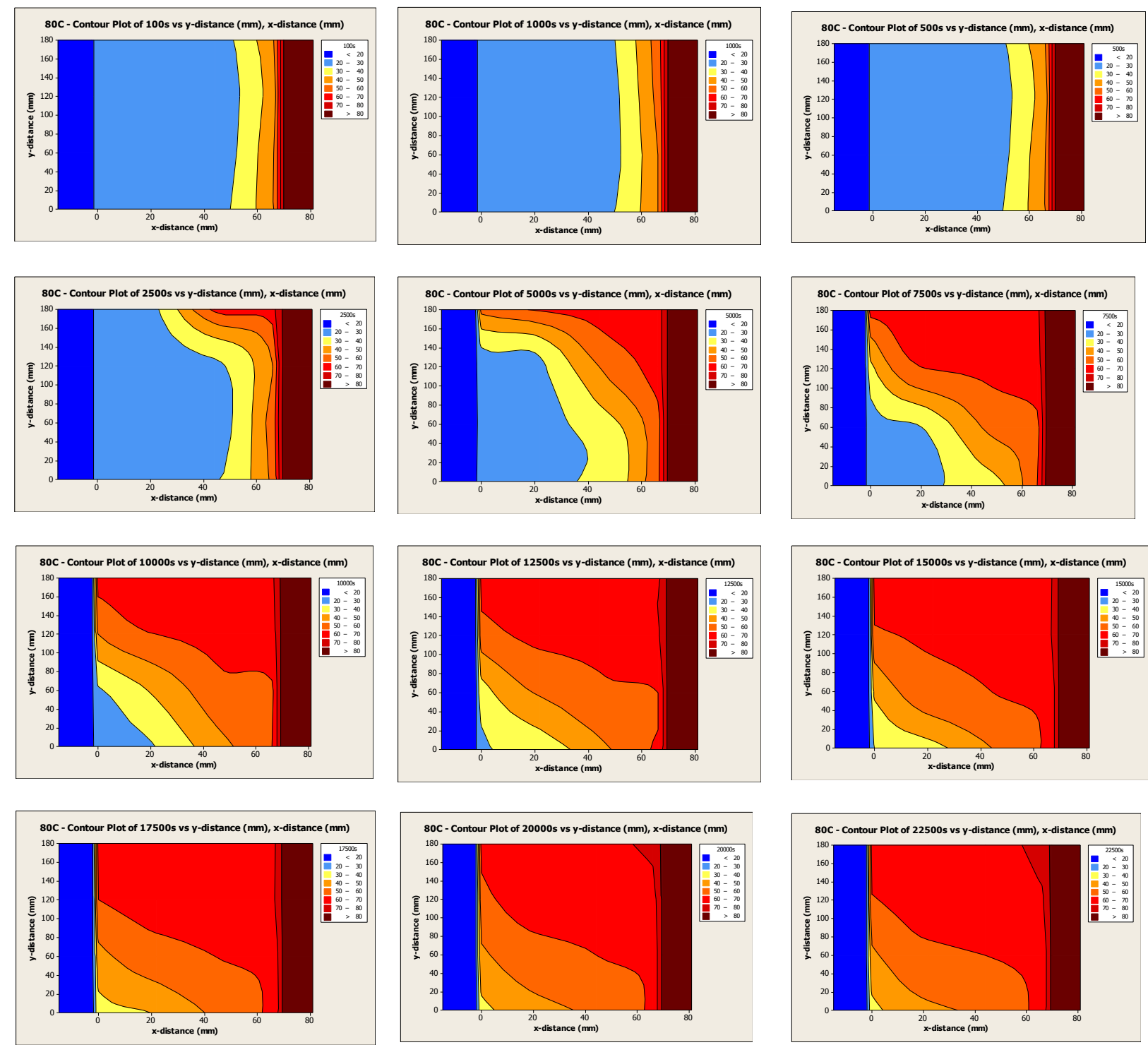

Figure 7. Samples of temperature contours progression with time for hot wall temperature of $80.1^{\circ} \mathrm{C}$. The dark red represent the hot water, the blue represent the cold water. The gradual change from red to blue reflect the change of local temperatures in the PCM cavity from hot wall temperature to cold wall temperature. The orange band effectively shows the range of melt transition temperature.

Figures $7(\mathrm{a}-\mathrm{I})$ presents the sample contours for a hot wall temperature of $80.1,{ }^{0} \mathrm{C}$ and indicates how the temperature profile of the PCM compartment changed over the period of the experimental run. The general trend is for melting to start parallel to the hot wall (Right hand side) and then progress from the top of the top right hand corner towards the lower left hand corner. The contours show clear temperature differences and the temperature rising from left to right and bottom to top of the cell. These temperature differences are of sufficient magnitudes to give rise to an anticlockwise convection current. 
If a convective flow is developed, the velocity is controlled by the vertical temperature gradient established adjacent to the hot wall. Figure 8 shows the temperature difference recorded by the infrared camera between positions T4 (top of hot wall) and T16 (bottom of hot wall) for each hot wall temperature. Each trace shows a rise in difference to a steady state suggesting the convection rate becomes constant once the temperature difference is established. As the wall temperature is increased, the rate at which the temperature difference is established increases as does the steady state absolute temperature difference suggesting a faster on set of convection and faster rate of convection at higher temperatures. The $53{ }^{\circ} \mathrm{C}$ data set is different to the hotter temperatures. The onset of development of the temperature difference is delayed for 460 minutes suggesting a much slower melt rate than the higher temperatures. The results are further discussed in conjunction with the melting profiles later in the paper

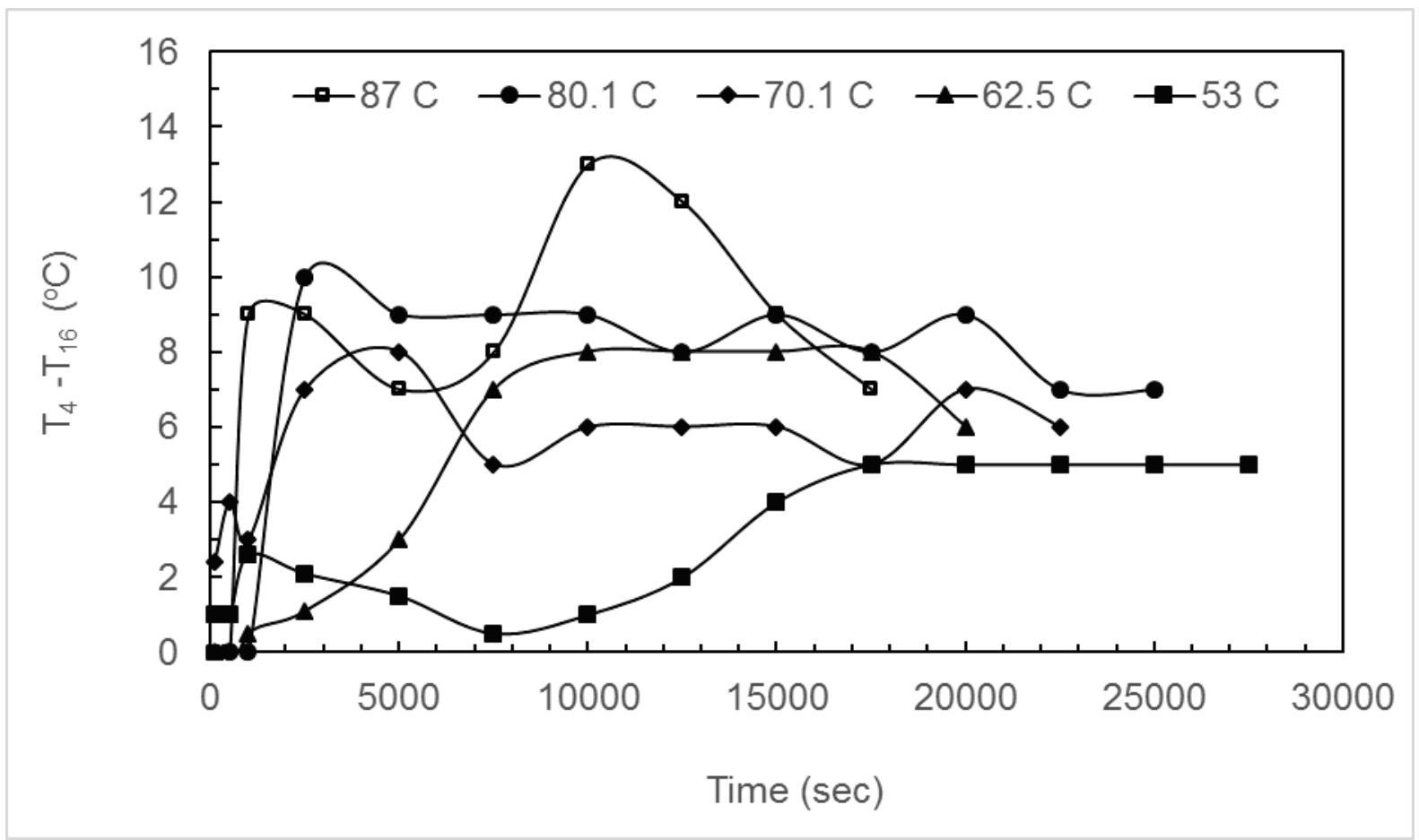

Figure 8. Variation of temperature difference recorded by the infrared camera between positions T4 (top of hot wall) and T16 (bottom of hot wall) for each hot wall temperature.

\subsection{Visual Observation and Data Deduction from the melting of PEG 1500 (Melt Profile)}

A digital camera was used to capture the melt profile of the solid PCM block as the melt front progresses. Figure 9 presents a sequence of photos illustrating the melting 
process of the PEG 1500 for cold and hot wall temperatures of $19.6^{\circ} \mathrm{C}$ and $80.1^{\circ} \mathrm{C}$ respectively. In these photographs, the white areas represent the solid PCM and the gold area represents the melted PCM.

For the 100s and 500s examples, a thin layer of melted PCM appeared adjacent to the hot wall. This indicated that the heat transfer mechanism was predominantly conduction. This mode of heat transfer dominated because the fluid was at this point relatively cold and viscous. The high viscous drag supresses' circulation and thus the melt front was almost uniform and parallel to the hot wall.

Once this initial stage had passed, buoyancy effects in the melt region became significant as the fluid warmed up and viscosity dropped causing faster transformation of the solid phase into liquid phase. As time progressed within the experiment, the buoyancy forces became large enough to overcome the viscous drag and initiate natural convection within the melted region. The hotter, melted material concentrated toward the top of the compartment and the convective motion reduced the resistance to heat transfer between the solid and the liquid. Taken together these two effects caused the PCM in the upper part of the compartment to melt more quickly than the base of the block. The higher melt rate due to the circulating current in the top of the PCM enclosure eventually created a concave curve at the top of the melt front (Figure 9(c-d)).

As melting progressed, the natural convection current was strengthened and its effect on the melt front became increasingly prominent. The increasing curvature of the upper part of the melt front provides a definite indication of this influence. By the time the melt front approached the cold wall at the upper part of the container the increased heat transfer had changed the shape of the melt front to a convex curve (Figure 9e).

After the melt front reached, the opposite side of the container (Figure 9f) the melt front started to descend the tank and the shape of the interface at the top portion of the solid PCM now became concave. It should be noted that a very thin layer of PCM does not melt adjacent to the cold wall because the wall temperature is significantly less than the melting point of the PCM. 


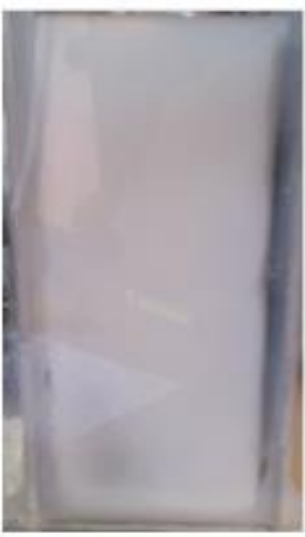

(a) $\mathrm{t}=100 \mathrm{sec}$

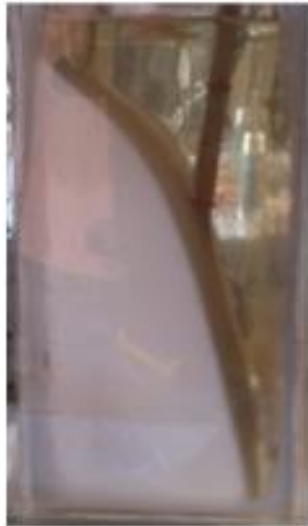

(e)t $=5000$ sec

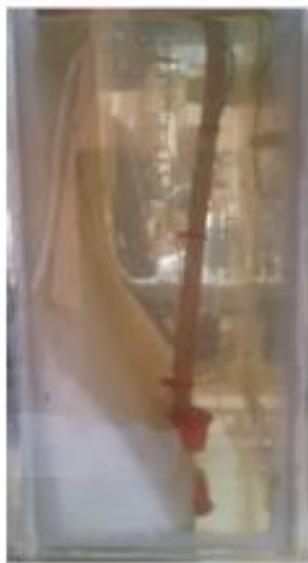

(i) $t=15000 \mathrm{sec}$

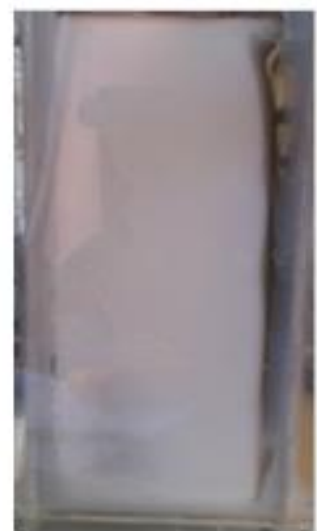

(b) $t=500 \mathrm{sec}$

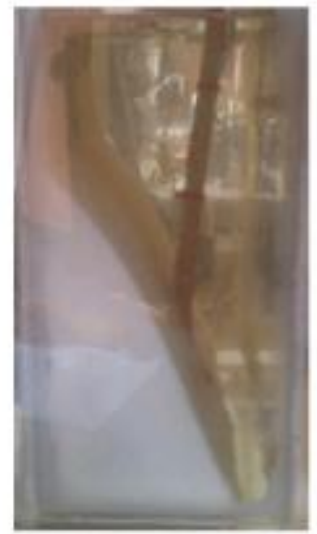

(f) $t=7500 \mathrm{sec}$

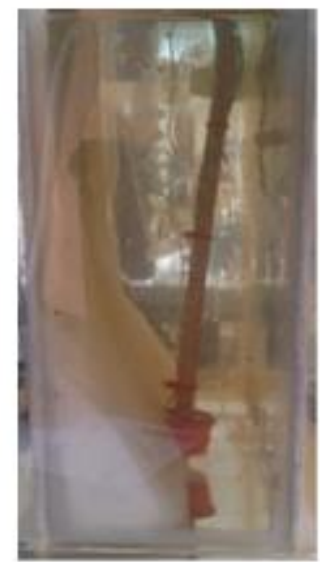

(j) $t=17500 \mathrm{sec}$

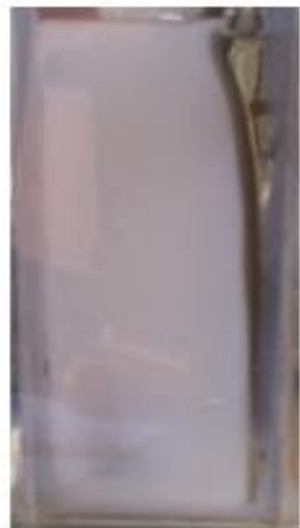

(c) $t=1000 \mathrm{sec}$

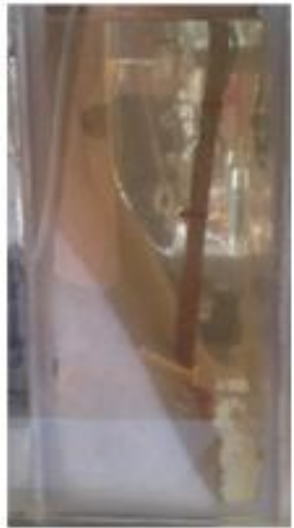

(g) $t=10000 \mathrm{sec}$

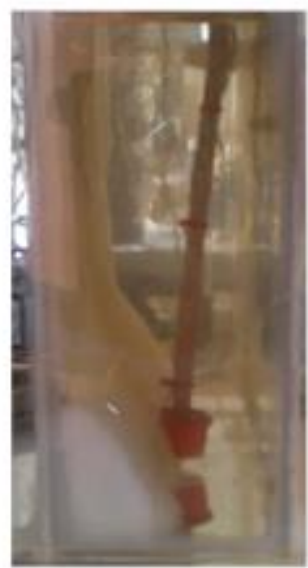

(k) $\mathrm{t}=200000 \mathrm{sec}$

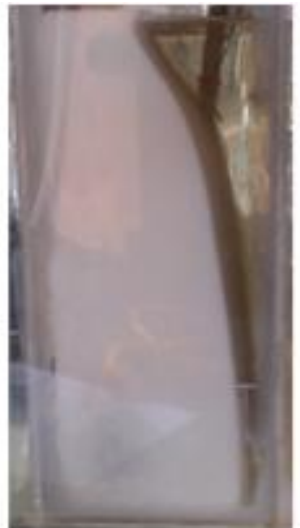

(d) $\mathrm{t}=2500 \mathrm{sec}$

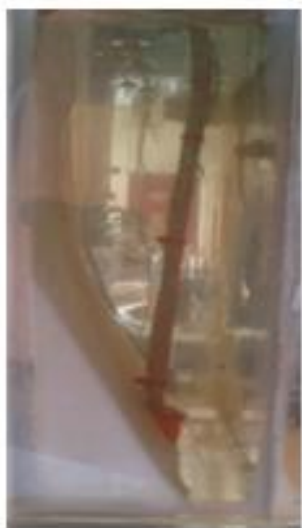

(h) $t=12500 \mathrm{sec}$

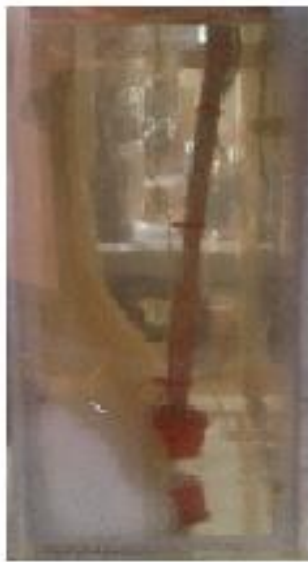

(L) $t=22500 \mathrm{sec}$

Figure 9. Sequence of photographs depicting the melting front progression with time (hot wall temperatures $=80.1^{\circ} \mathrm{C}$ and cold wall temperature $=19.6^{\circ} \mathrm{C}$ ).

To make the photographs more useful they were converted into cumulative time elapsed contours. Contours were created by measuring the horizontal distance between the cold wall and the melt front position, at intervals of $20 \mathrm{~mm}$ from the 
surface of the initially molten PCM. Figure 10a summarises the changes seen in the melt front profile derived from the photographs presented as in Figure $9(a-k)$.

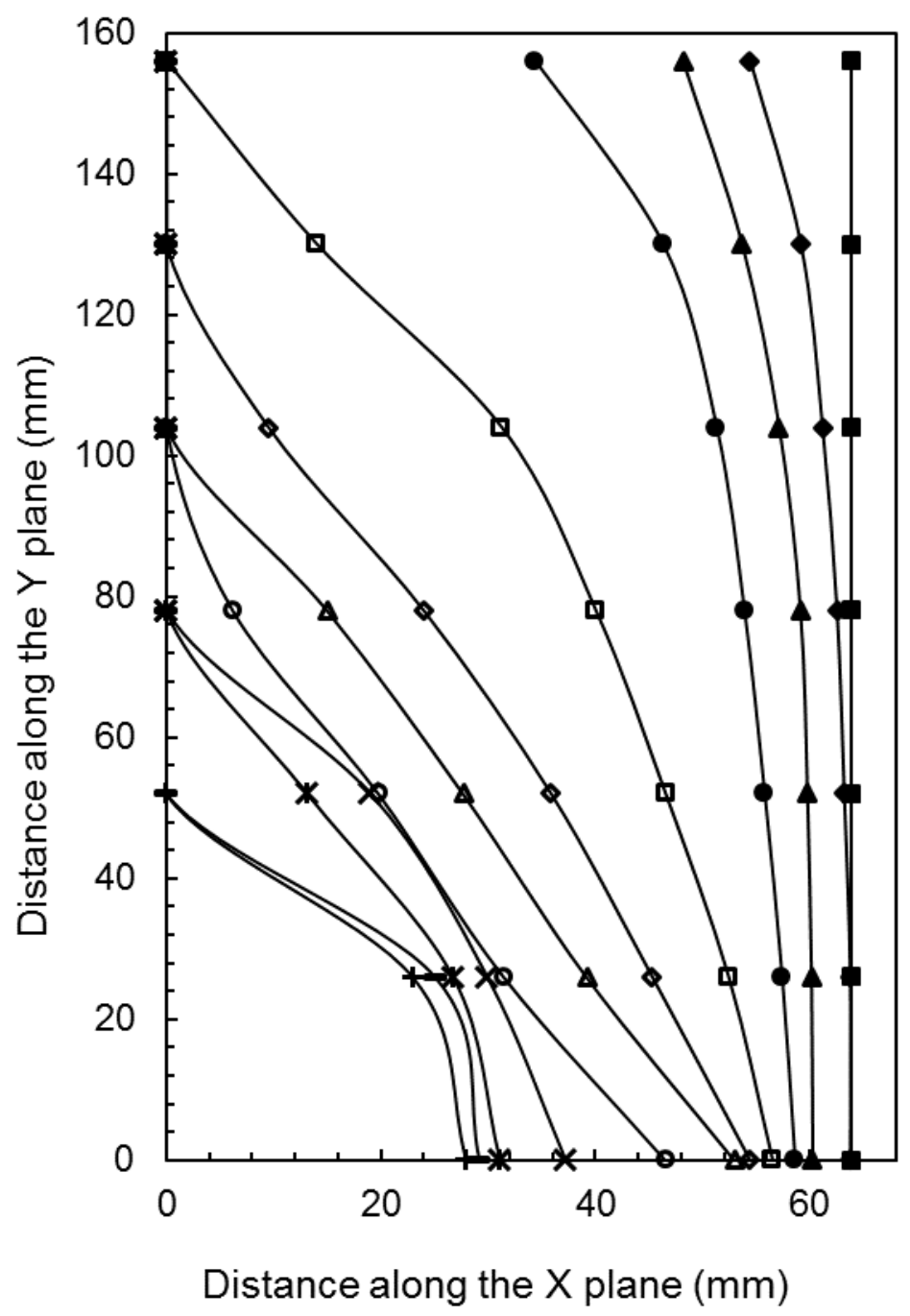

Figure 10a. Time elapsed contours of the melt front position (wall temperature $=80 \cdot 1^{\circ} \mathrm{C}$ ). (The legends used in this Figure are the same legends used in Figure 10b.) 


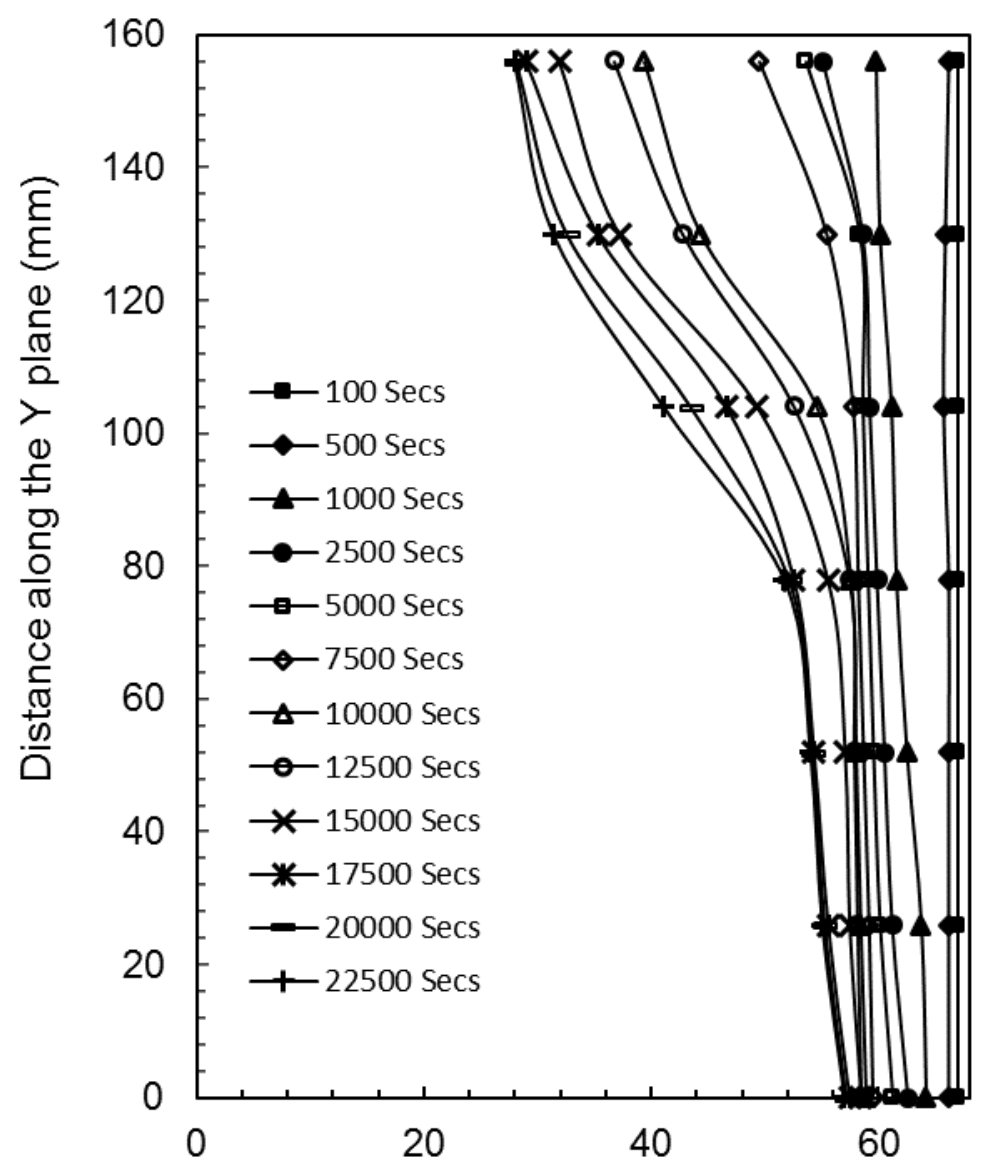

Distance along the $X$ plane $(\mathrm{mm})$

Figure 10b. Time elapsed contours of the melt front position (wall temperatures $=$ $\left.53^{\circ} \mathrm{C}\right)$ 


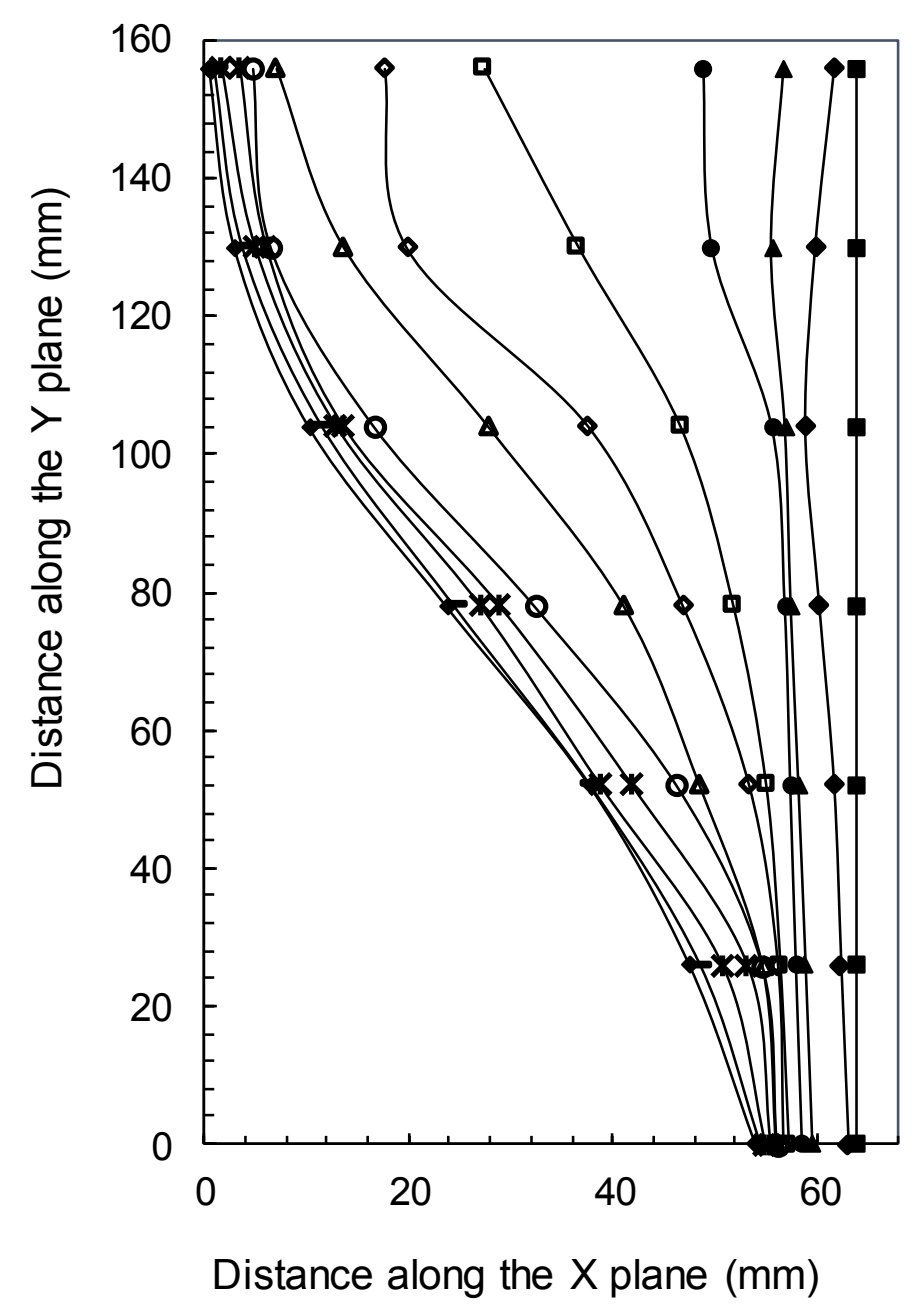

Figure 10c. Time elapsed contours of the melt front position (wall temperatures $=$ $62.5^{\circ} \mathrm{C}$ ). (The legends used in this Figure are the same legends used in Figure 10b.) 


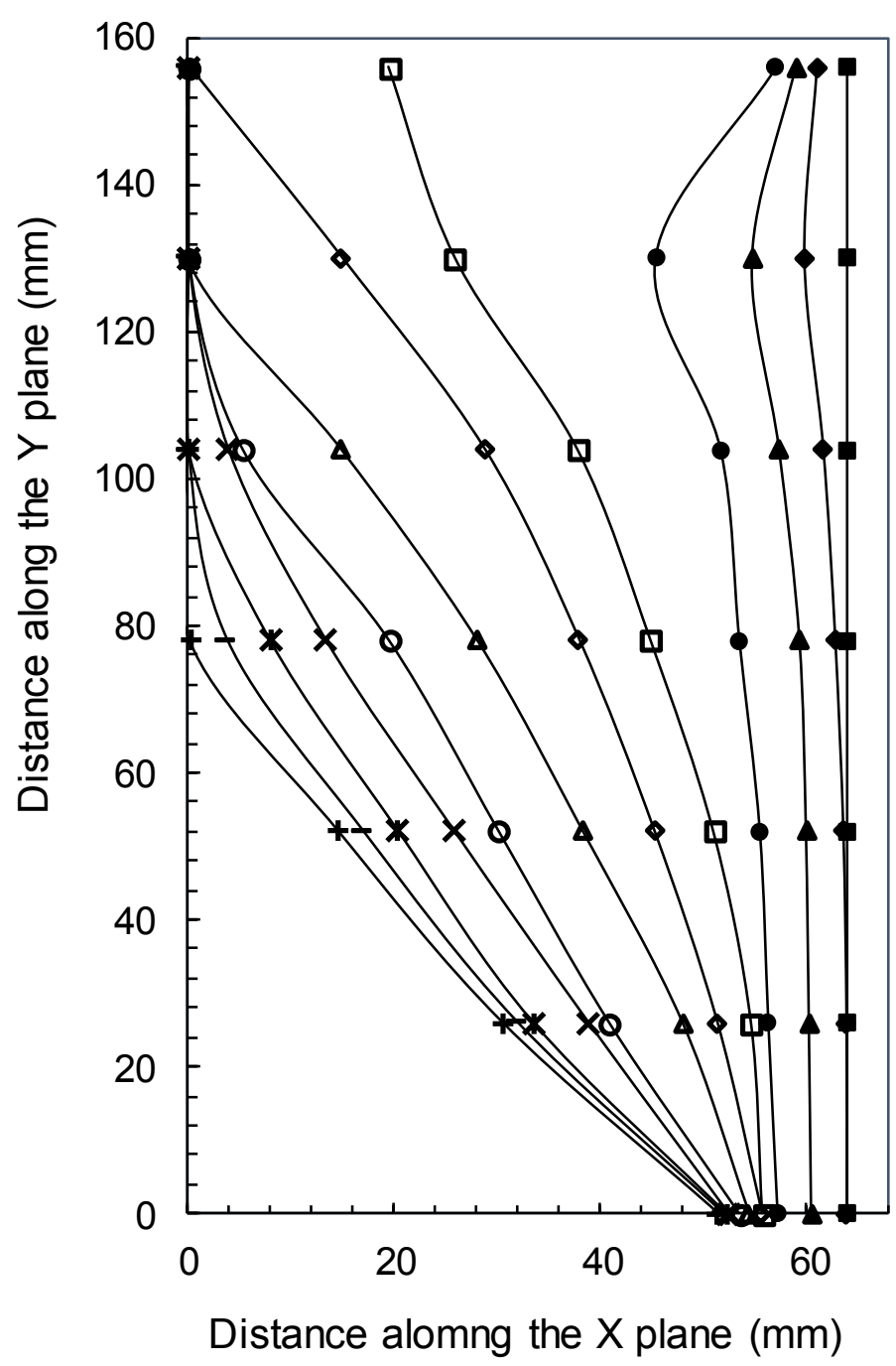

Figure 10d. Time elapsed contours of the melt front position (wall temperatures $=$ $70.1^{\circ} \mathrm{C}$ ). (The legends used in this Figure are the same legends used in Figure 10b.) 


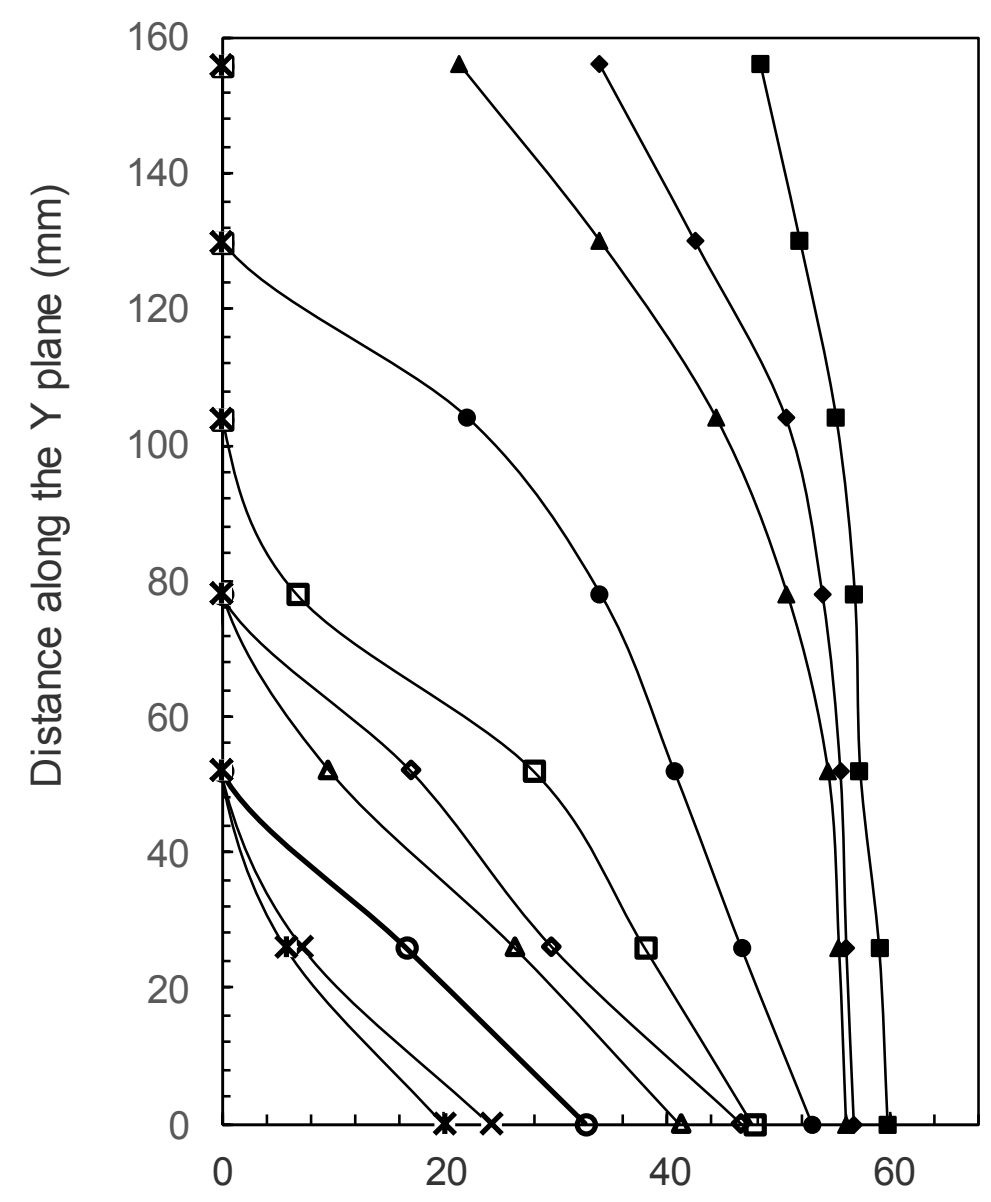

Distance along the $\mathrm{X}$ plane $(\mathrm{mm})$

Figure 10e. Time elapsed contours of the melt front position (wall temperatures $=$ $87^{\circ} \mathrm{C}$ ). (The legends used in this Figure are the same legends used in Figure 10b.)

Similarly Figures $10 \mathrm{~b}-\mathrm{e}$, present the corresponding cumulative time elapsed contours of fraction melted for the hot wall temperature measurements made at 53 , $62.5,70.1$ and $87^{\circ} \mathrm{C}$ respectively. The total amount of melt achieved in each case reduces with temperature of the hot wall and in the case of the $53^{\circ} \mathrm{C}$ the melt front fails to reach the cold wall indeed barely crossing the half way point of the cell.

In general the temperature profiles obtained from the thermocouple and infrared camera measurements (see Figure 7) are in agreement with the time elapsed contours obtained from the photographic record (see Figure 10b) giving mutual confidence in the results obtained by each method.

It is apparent from the discussion of the behaviour of the melting development that the melting rate is directly related to the hot wall temperature, which produces 
different strengths of natural circulation based on the temperature difference between the top and bottom of the PCM enclosure (Figure 8). The present finding is supported by the Kamkari et al. (2014) and Yanxia (2007).

\subsection{Effect of hot wall temperature on melting rate}

ImageJ pixel counting software was used to calculate the melt area \% from the photographs presented in Figure 9(a-f). Each image was imported into the imageJ software, the depth of the solid PCM was used to calibrate the scale and the fraction melt area $F_{r}$ was then computed using equation 1 :

$$
\% F_{r}=\frac{M_{f}}{A_{t}} * 100
$$

Where $\mathrm{F}_{\mathrm{r}}$ is the melted fraction of PCM at time $\mathrm{t}, M_{f}$ the area of melted PCM at time $\mathrm{t}$ and $A_{t}$ is the total area of the solid PCM at the start. The melt fraction are plotted as a function of time for dataset1 in Figure 11a.

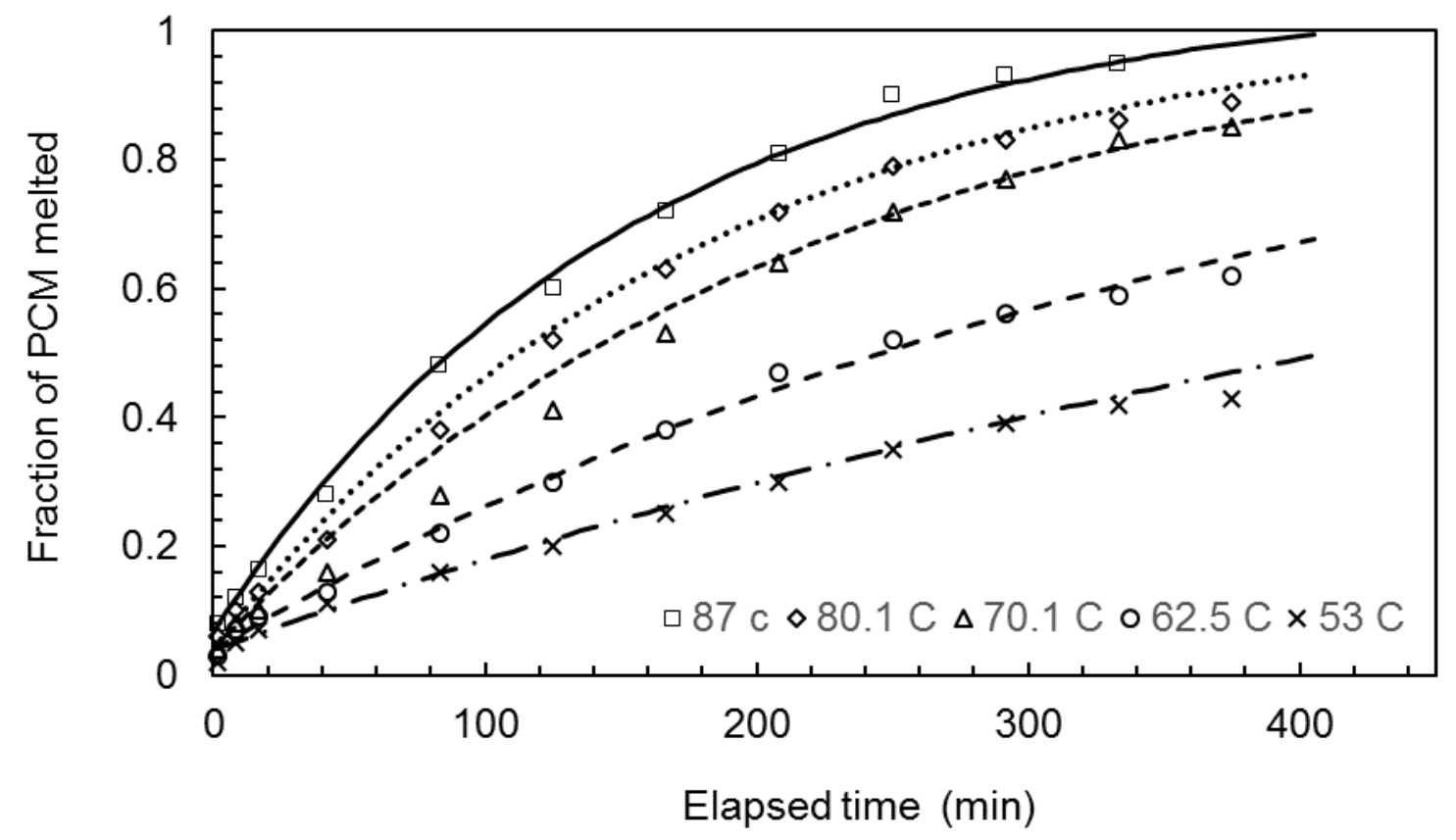

Figure 11a. Fraction amount of melted PCM plotted as a function of elapsed time for different hot wall temperatures $\left(87,80.1,70.1,62.5\right.$ and $\left.53^{\circ} \mathrm{C}\right)$

The results appear to show an exponential rise to a limit of the melting rate and have been fitted with an equation of the form: 


$$
F r=A+\left(1-e^{-k t}\right)
$$

Where $F_{r}$ is the fraction PCM melted, $t$ the time elapsed and $A$ and $K$ are fitted constants for each temperature. The fitted parameters for the curves presented in Figure $11 \mathrm{~A}$ shows a constant value for $\mathrm{A}$ of 0.04 for all data sets apart from the $80.1^{\circ} \mathrm{C}$ set which has a value of 0.067 . The $A$ value accounts for the offset in the melt front data when the hot water is applied to the hot reservoir during the unsteady state period as the hot reservoir temperature is established. The higher value of $A$ for the data set for $80.1^{\circ} \mathrm{C}$ may be attributed to the calculation of the melt area at initial stage of the experiment when melt areas are small (as explained in section 3.7).

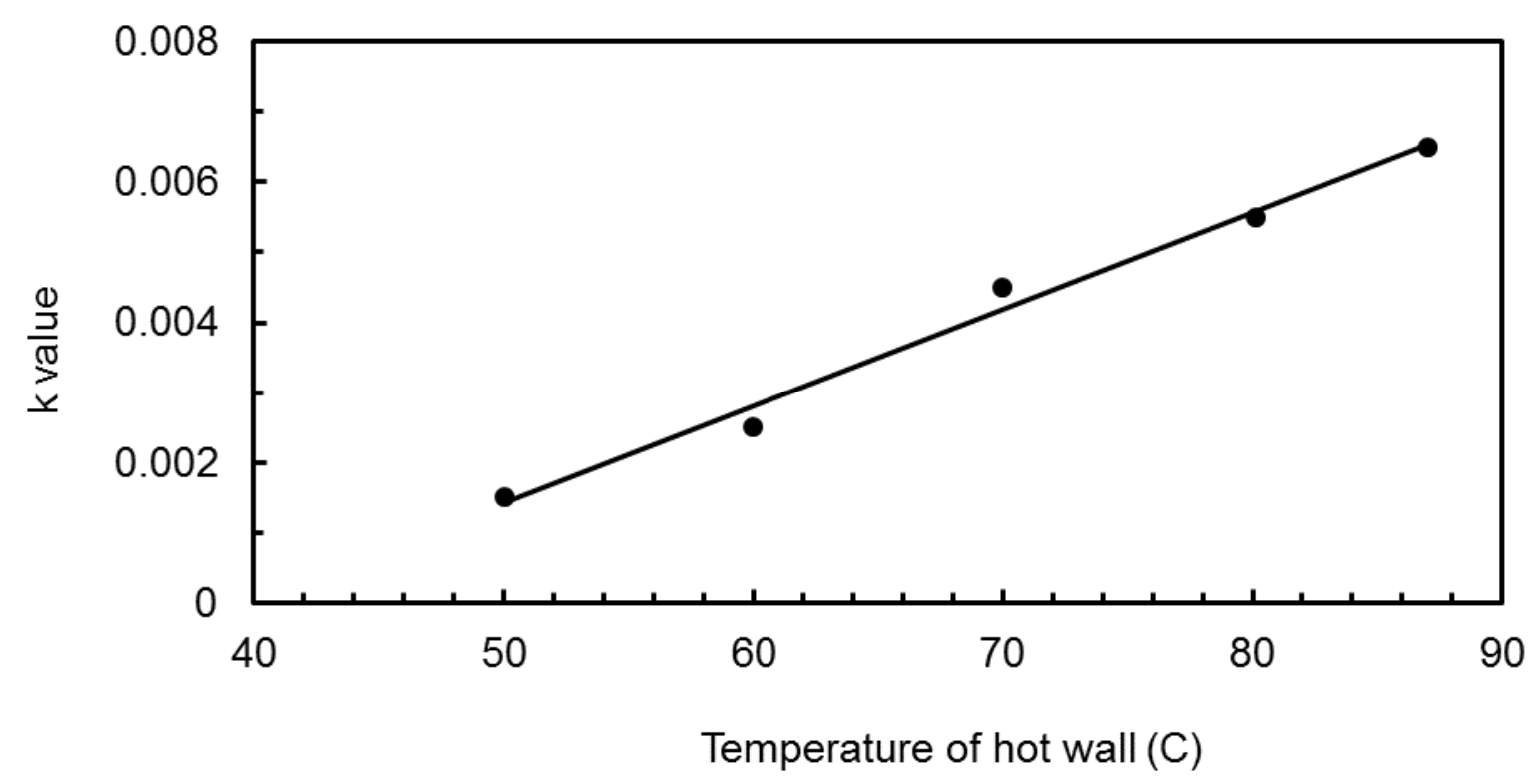

Figure 11b Fitted parameter $\mathrm{k}$ from equation 2 used to model fraction of amount of melted PCM plotted as a function of temperature.

The $\mathrm{k}$ values are presented in Figure $11 \mathrm{~b}$ and show a linear rise in the value of $\mathrm{K}$ with temperature. This may offer a simple way forward in predicting the melt rate for other temperatures. A similar melting behaviour was reported by Wang et al. (1999), Yanxia (2007) and Joulin et al (2011). The value of $k$ can be estimated as:

$$
K=0.000138 T_{h}-0.0058
$$

This transient melting process associated with buoyancy-driven convection is governed by number of dimensionless parameters including Rayleigh number, Fourier number and Stefan number. The Rayleigh number describes the importance 
of the buoyancy force to the diffusion force and can be defined as (Niemela et al (2000); Nabeel and Khodadadi, (2015)):

$$
R a=\frac{g \beta\left(T_{h}-T_{m}\right) H^{3}}{\alpha v}
$$

Fourier number (Fo) is a dimensionless parameter characterizing the transient heat transfer behaviour as a ratio between thermal diffusivity and thermal energy storage rate (Yunus and Turner). Fourier number was defined as (Nabeel and Khodadadi (2015))

$$
F o=\frac{t \alpha}{L^{2}}
$$

Total melting of the PCM was not achieved in any experiment. The time taken to melt $40 \%$ of the total PCM in the chamber was used as the basis to calculate the Fourier number because it is the highest common percentage melt achieved at all hot water temperatures.

Finally the Stefan number (Ste) represents the sensible heat to latent heat ratio in the storage medium and is given as (Wang et al (1999)):

$$
\text { Ste }=\frac{c\left(T_{h}-T_{m}\right)}{h_{s l}}
$$

A summary of the data are given in Table 1.

Table 1. The values of dimensionless number for each hot wall temperature

\begin{tabular}{|c|c|c|c|c|}
\hline $\begin{array}{l}\text { Hot wall } \\
\text { temp. (K) }\end{array}$ & $\begin{array}{c}\text { Cold wall } \\
\text { temp. (K) }\end{array}$ & Rayleigh number & Stefan number & Fourier number \\
\hline 87 & 19 & $3.65 \mathrm{E}+08$ & 0.53813 & 0.008034 \\
\hline 80.1 & 19 & $3.04 \mathrm{E}+08$ & 0.44756 & 0.011124 \\
\hline 70.1 & 19 & $2.14 \mathrm{E}+08$ & 0.315 & 0.016315 \\
\hline 62.5 & 19 & $1.47 \mathrm{E}+08$ & 0.21656 & 0.02163 \\
\hline 53 & 19 & $6.24 \mathrm{E}+07$ & 0.09188 & 0.03708 \\
\hline
\end{tabular}




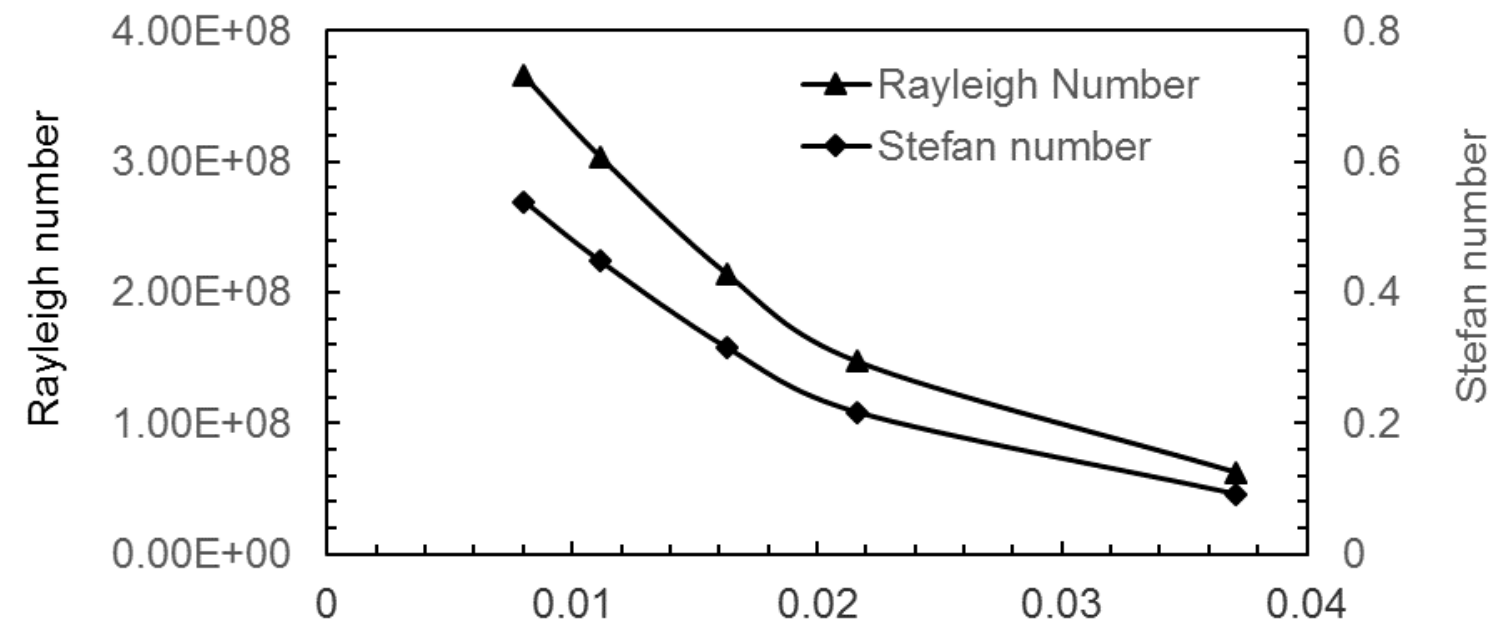

Fourier number

Figure 11c. Variation of Rayleigh Number and Stefan number with Fourier number.

The data in Table 1 are plotted in Figure 11c. it can be observed that the Rayleigh number increases (increase in the buoyancy effects due to an increase in the hot wall temperature) for low Fourier number (smaller melting time). A similar trend can be observed for Stefan number with Fourier number. The results also show that the relationships are nonlinear. The present result is supported by the data from Christiano and Luiz (2011).

The differential change in melting rate as a function of time $(\mathrm{dFr} / \mathrm{dt})$ is shown in figure 12 and interestingly shows a similar trend to the Nusselt number plotted as a function of Fourier number presented by (Wang et al. (1999) and Kamkari and Shokouhm (2014)). 


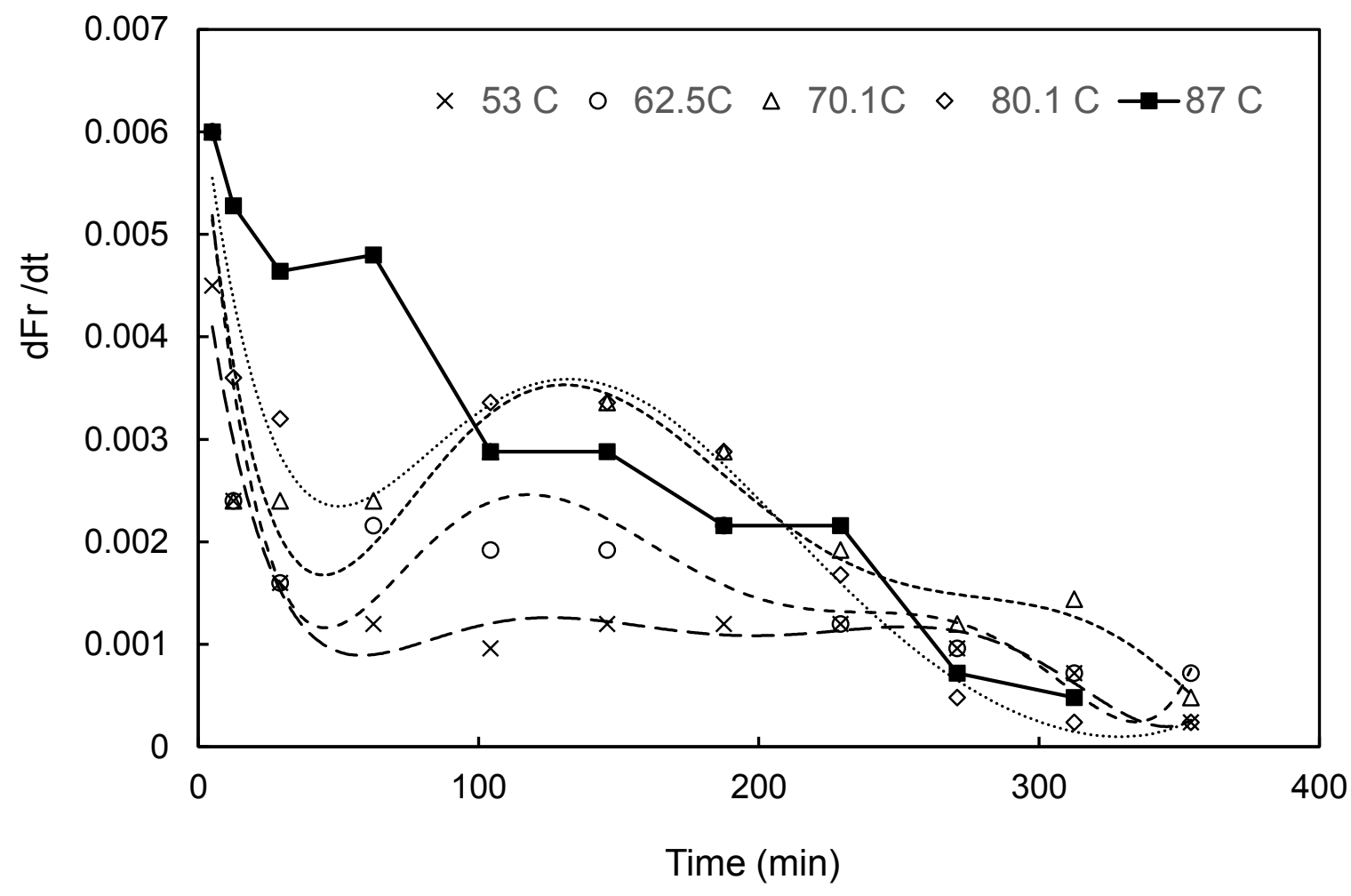

Figure 12. Variation of the melt rate versus the elapsed time (note: only the data collected at $80.1,70.1,62.5$ and $53^{\circ} \mathrm{C}$ are presented in this plot)

For the $80.1,70.1,62.5$ and $53^{\circ} \mathrm{C}$ records, the rate of change of the melt rate follows a distinct complex pattern that cannot be fitted by the differential form of equation 2 . During the first 10 minutes, the change in the rate of melting is observed to reduce sharply. This appears to coincide with the conduction phase controlled part of the experiment identified from Figure 10 and is understandable given the increase in path length to the melting face.

The change in rate of melt is then observed to rise. The rate of rise is higher for the higher wall temperatures and appears to coincide with the onset of convection detected in Figure 9. The rates of change are observed to reach a maximum and start to fall. It is possible that a third factor comes into play the thickness of the solid PCM has reduced and in some cases; the melt phase has reached the cold wall. The resistance to heat transfer to the cold wall due to the insulating properties of the solid PCM has been reduced. Therefore, the rate of heat loss to the cold wall is increased if more of the available heat is lost to the cold wall then the heat available for melting is turned down and the melt rate is reduced. 
The melt rate could therefore be represented by heat transfer equation of the form:

$$
Q=-k_{1} A_{h} \frac{\Delta T_{1}}{\Delta x_{1}}-h A_{h}-k_{2} A_{h} \frac{\Delta T_{2}}{\Delta x_{2}}
$$

Where $Q$ is the amount of heat transferred to the PCM, the first term refers to the heat conducted through the melted PCM to the solid interface, term 2 is the convective heat transfer across the solid liquid interface and term 3 is the conduction through the solid PCM to the cold wall.

The rate of convection is significant and increases as the hot wall temperature rises. In the case of the $87^{\circ} \mathrm{C}$ data set, convection is so fast that the melt front has reached the cold wall before convection has reached steady state and the heat loss directly to the cold sink begins to control. This factor affects the pattern for the rate of change of the melt rate with time for the $87^{\circ} \mathrm{C}$ dataset and it does not show the sharp rise in melting observed due to convection seen for the other data sets. This is because the convection effect is still establishing as heat is being lost directly to the cold sink and it is being overshadowed by the heat losses directly to the cold wall.

\subsection{Effect of cold wall temperature}

Data set 2 was measured using a constant hot wall temperature of $80.1 \mathrm{C}$ and cold wall temperatures of $35,19.6,10$ and $2^{\circ} \mathrm{C}$ to investigate the effect of cold wall temperature on the melting rate. The results were treated in the same way as the hot wall variations for set 1 and fraction melt results are presented as Figure 13a.

The result as plotted in the Figure 13 a seem to show that initially up to 100 minutes all temperatures exhibit the same linear behaviour suggesting that up to this point the residual amount of the solid PCM is sufficient to prevent the cold temperature from having a significant effect on the melt rate.

Figure 13b shows the melt front for the four cold temperatures at 83 minutes. It can be observed that the melt fronts for the 2 and $9{ }^{\circ} \mathrm{C}$ data sets haven't reached the cold wall, the $19.6{ }^{\circ} \mathrm{C}$ has just reached the wall face and $1 \mathrm{~cm}$ depth was melted from the cold wall face for $35^{\circ} \mathrm{C}$ data set. The locations of melt front relative to the cold wall explain the linear behaviour of the fraction of PCM melt in figure 13a. This implies that a minimum thickness of PCM can be set to isolate the pipe from cold 
wall effects. To determine this thickness, measurements are needed for a cylindrical geometry.

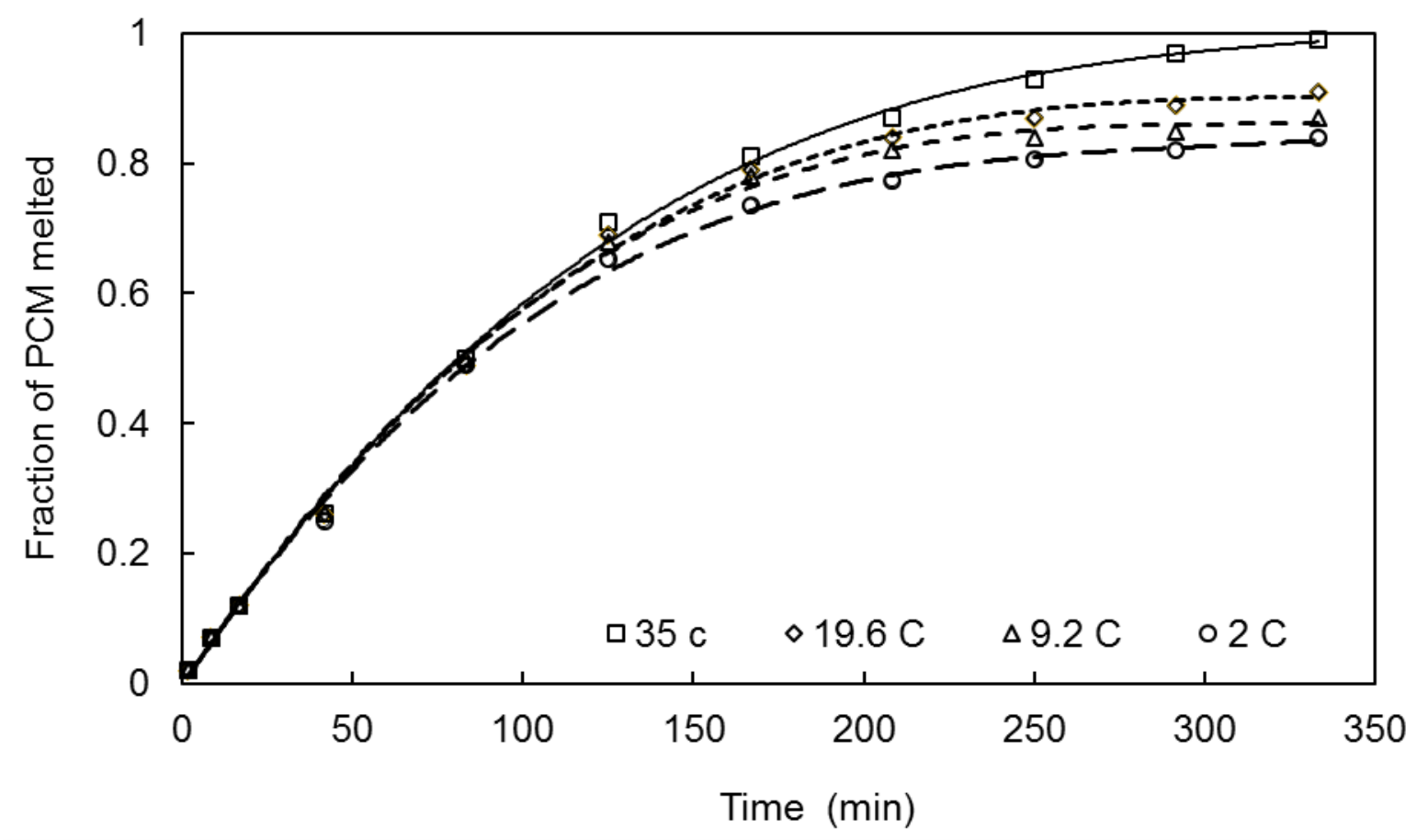

Figure 13a. Fraction of amount of melted PCM plotted as a function of elapsed time for different cold wall temperatures

Beyond 130 minutes the data sets become curved and start to diverge indicating the heat transmission through the solid is now a contributing factor, lower temperatures lead to lower melt rates, given more heat is lost more quickly to the heat sink and the therefore the solid melts more slowly. It should be noted the divergence between the curves observed for changing cold wall temperatures is much less than that seen in Figure 11a confirming the hot wall temperature is dominant due the convection in the liquid phase being controlled by the hot wall temperature. 


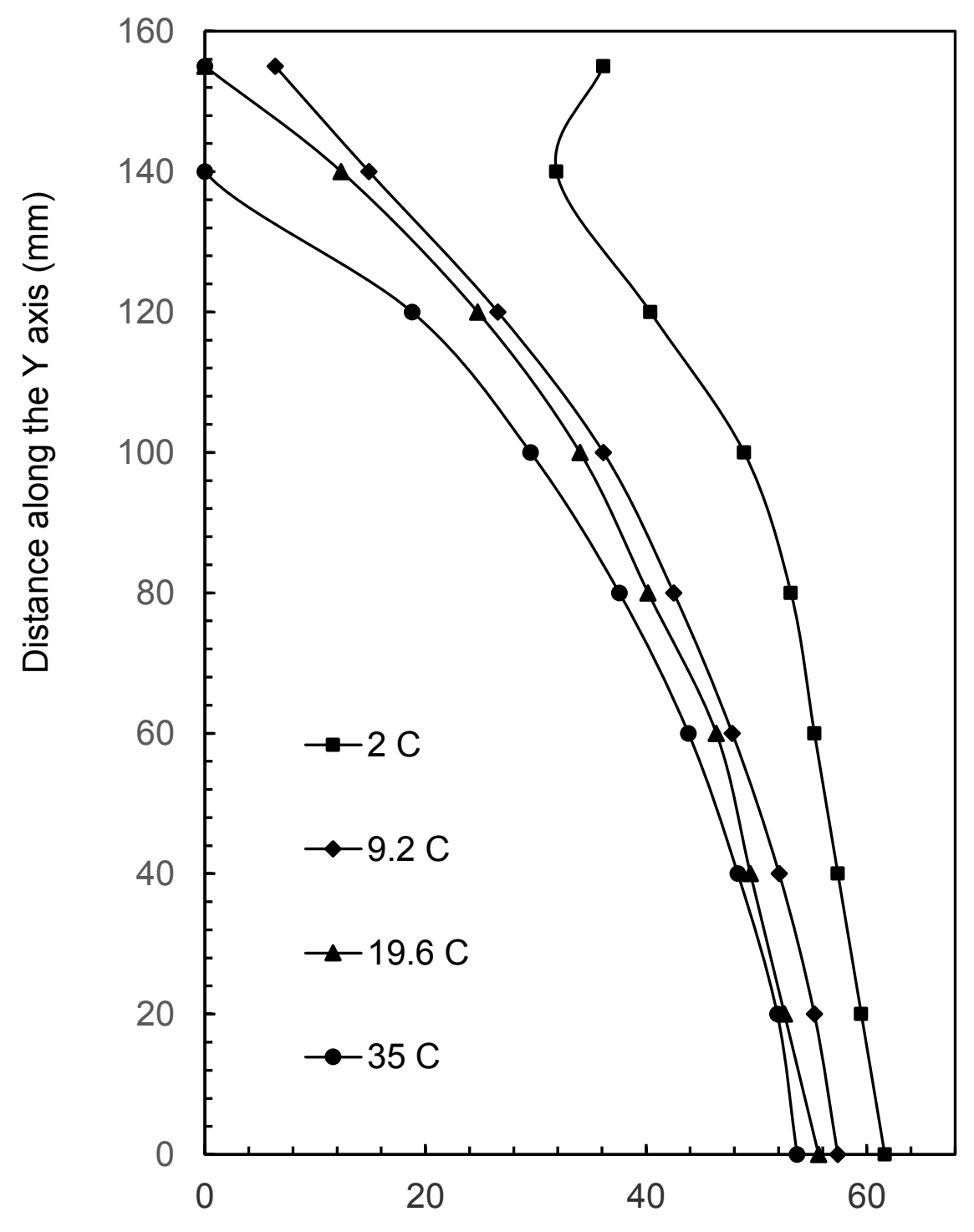

Figure 13b Time elapsed contours of the melt front position for different cold wall temperatures at 83 minutes from start of experiments (hot wall temperatures = $\left.80.1^{\circ} \mathrm{C}\right)$.

Figure 14 presents the change in melt rate with elapsed time for dataset 2. All data sets exhibit the same characteristic shape, which is different from the hot wall datasets in Figure 12. Only small deviations between the curve are seen that seem to reduce the rate systematically as the temperature is dropped. This is consistent with cold wall temperature only affecting the rate of conduction through the solid PCM and would produce a near linear offset with reducing temperature. 


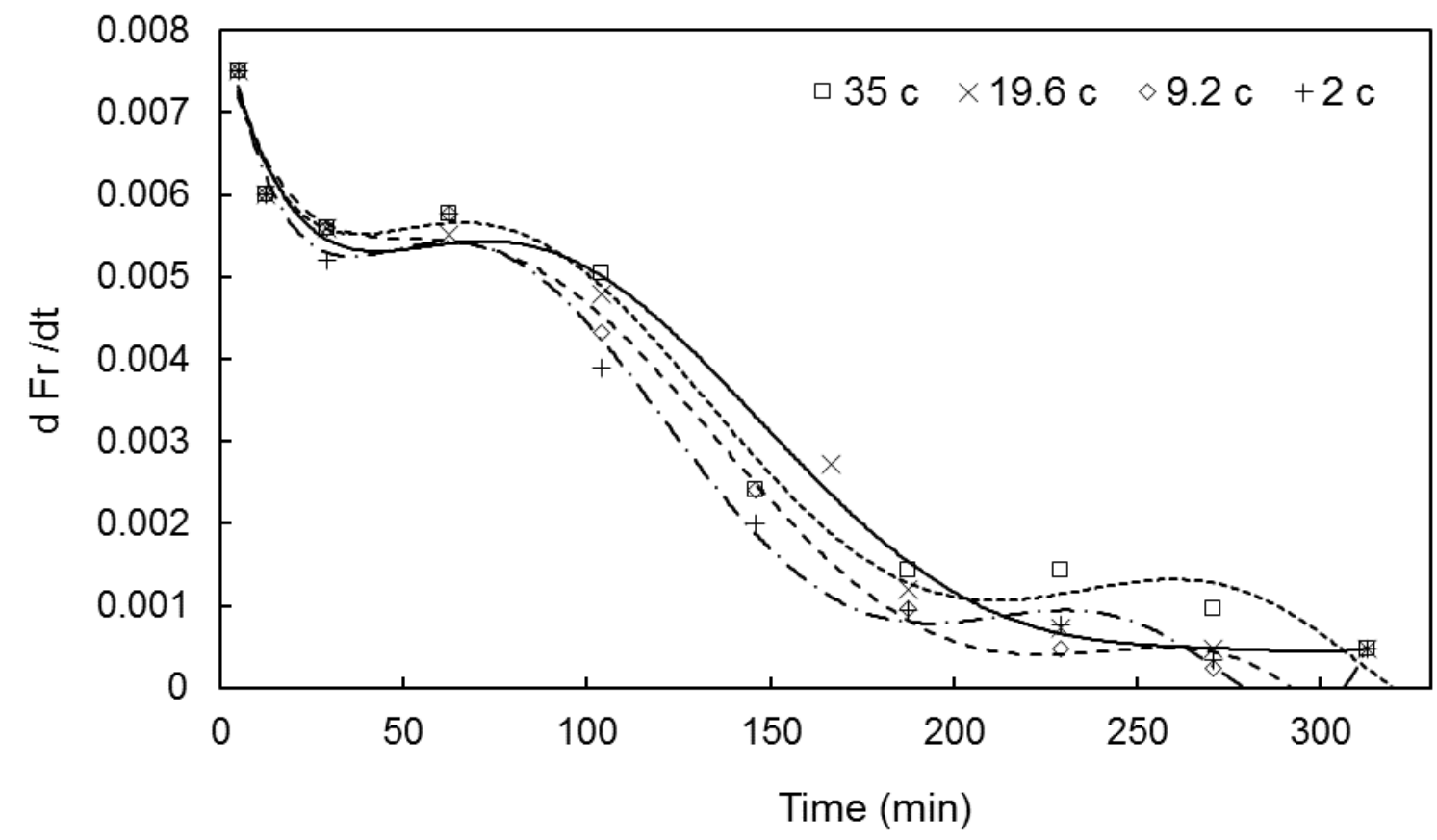

Figure 14. Variation of the rate of melt with time at a constant hot wall temperature of $80.1^{\circ} \mathrm{C}$

\subsection{Tracer Dye Studies at High Temperature}

Finally, to confirm the presence of convection currents a single dye tracer study was performed at a temperature of $80.1^{\circ} \mathrm{C}$ for the hot wall and $19.6^{\circ} \mathrm{C}$ for the cold wall. After one hundred and eighty minutes, a single drop of dye was added to the PCM enclosure and the motion of the dye was recorded using a video. The melted PCM movement at the outer boundary of the melted zone is presented in Figures 15(a-d) as a series of still photographs.

It was discovered that it took approximately six minutes for the dye to circulate round the enclosure. The circulation is clearly in an anticlockwise direction (moving from right to left across the top of the enclosure, sliding down the melt face towards the bottom right hand corner then rising vertically (parallel to) up the hot face. The highest liquid velocity is seen along the melt front and the hot wall. 


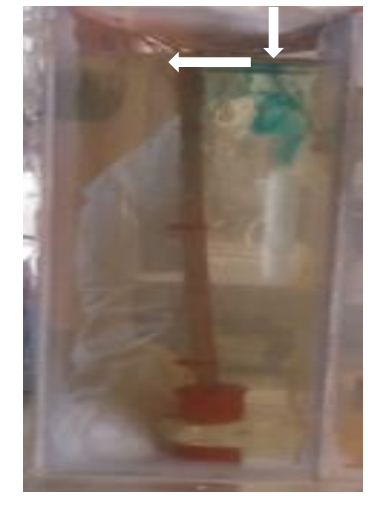

a@ time of 0 min

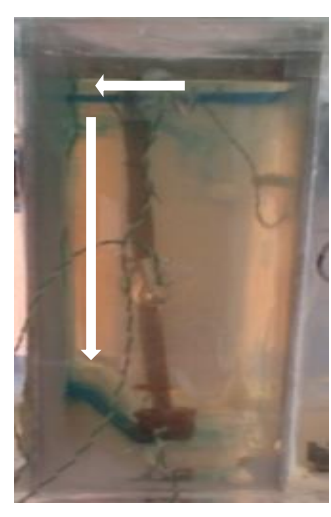

$b @$ time of 3mins
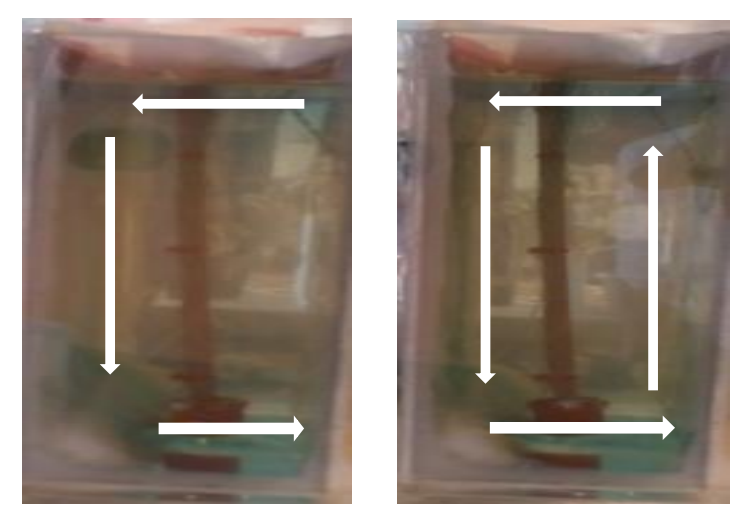

$c @$ time of 4 mins

$d @$ time of 6mins

Figure 15. Images showing the dye tracer introduction and velocity profile structure with respect to time

\subsection{Experimental uncertainty}

The experimental results are always influenced by the inaccuracy in measurement of individual instruments. In present work, the uncertainty can be generated from temperature measurements using both thermocouple and infrared, the contours of melt front and the fraction of melted PCM.

The error in temperature measurement by thermocouples was discussed in section 2.4. All thermocouples are set in a solid PCM for 24 hours to check that they are registering the same temperature. The results show a limit of consistency between all two wire K-Type thermocouples of $\pm 0.2^{\circ} \mathrm{C}$ that is within the expected accuracy of this type of instrument (Burns and Scroger (1989)). More information on accuracy of individual K-type thermocouples was given by Alan Tong, (2001) which shows that for temperature in the range of $-200-1300$, the accuracy is $\pm 2.2^{\circ} \mathrm{C}$ and the sensitivity is approximately $41 \_$V/8C.

The error in melt front and fraction of melt could result from two sources. The first source is the error in identifying the outer boundaries of the PCM from the photos captured by a camera due the true wall edge of the PCM being obscured by the sealant used to seal the box walls and the light refraction/reflection across the transparent wall. The second source was from clearly identifying the melting front through the ImageJ software that is used to calculate the percentage. The error in melting front is estimated to be $\pm 3 \%$ based on an error of $2 \mathrm{~mm}$ in identifying the interface. The error in fraction of melt is estimated to be $4.2 \%$, based on $1 \mathrm{~mm}$ error in dimension measurement. 


\section{Conclusions}

From this study, it was established that at the initial stage of the experiment, the dominant mode of heat transfer was conduction from the hot wall to the PCM. As the experiment progressed more of the PCM became molten, the melted phase became hotter leading to temperature gradients within the melt phase and the establishment of convective circulation. At the end of the experiment when the melt front reached the opposite wall it was discovered heat loss directly to the cold wall became the dominant process.

For hot wall temperature, the results show a strong correlation between the hot wall temperature and the fraction melt as it control the convection heat transfer. The results also shows that the melt rate decrease steeply at the start of melting process for all cases except the case of $87^{\circ} \mathrm{C}$. Then, the melt rate behaviour changed from almost constant for low temperature $\left(53^{\circ} \mathrm{C}\right)$ to have a peak at around 125 minutes for hot higher wall temperatures $\left(62.5,70.1\right.$ and $\left.80.1^{\circ} \mathrm{C}\right)$. For hot wall temperature of $87^{\circ} \mathrm{C}$, the melt rate reduces gradually.

For cold wall temperature, the results show that the cold wall temperature has insignificant effect on fraction melt for a constant hot wall temperature. The variation of melt rate with the time has a similar characteristic shape for all cold wall temperatures used in this study. A dye tracer study shows the natural circulation in the liquid zone, confirm the presence of the strongest convection at the solid-liquid interface and reveal the velocity profile/current direction. An approximate time of six minutes was recorded for the circulation of the solution round the enclosure giving approximate velocity of $0.00117 \mathrm{~m} / \mathrm{s}$.

\section{References}

Alan Tong, Improving the accuracy of temperature measurements, Sensor Review, Vol. 21 Issue: 3, (2001), 193-198.

Alkilani, M. M., Sopian, K., Alghoul, M. A., Sohif, M., \& Ruslan, M. H., Review of solar air collectors with thermal storage units. Renewable and Sustainable Energy Reviews, 15(3), (2011), 1476-1490.

Ahmad M, Bontemps A, Salle H, Quenard D., Experimental investigation and computer simulation of thermal behaviour of wallboards containing a phase change material. Energy and Buildings 38(4), (2006), 357-66. 
Arunkumar, T., Denkenberger, D., Ahsan, A., \& Jayaprakash, R., The augmentation of distillate yield by using concentrator coupled solar still with phase change material. Desalination, 314, (2013), 189-192.

Assis, E., Katsman, L., Ziskind, G., \& Letan, R., Numerical and experimental study of melting in a spherical shell. International Journal of Heat and Mass Transfer, 50(9), (2007), 1790-1804.

Benard, C., Gobin, D., \& Martinez, F., Melting in rectangular enclosures: Experiments and numerical simulations. Journal of Heat Transfer, 108, (1986), 174181.

Burns, G. W., \& Scroger, M. C., The calibration of thermocouples and thermocouple materials. NIST special publication 250-35, (1989).

Chiu, J. N. W., Heat Transfer Aspects of Using Phase Change Material in Thermal Energy Storage Applications. Stockholm: KTH School of Industrial Engineering and Management, (2011).

Dhaidan, N. S., \& Khodadadi, J. M, Melting and convection of phase change materials in different shape containers: A review, Renewable and Sustainable Energy Reviews 43, (2015), 449-477

Ettouney, H. M., Alatiqi, I., Al-Sahali, M., \& Ahmad Al-Ali, S., Heat transfer enhancement by metal screens and metal spheres in phase change energy storage systems. Renewable Energy, 29(6), (2004), 841-860.

Fok, S. C., Shen, W., \& Tan, F. L., Cooling of portable hand-held electronic devices using phase change materials in finned heat sinks. International Journal of Thermal Sciences, 49(1), (2010), 109-117.

Fukai, J., Hamada, Y., Morozumi, Y., \& Miyatake, O., Improvement of thermal characteristics of latent heat thermal energy storage units using carbon fiber brushes: Experiments and modeling. International Journal of Heat and Mass Transfer, 46(23), (2003), 4513-4525.

Gabriela, L., Thermal Energy Storage with Phase Change Material. Leonardo Electronic Journal of Practices and Technologies, (2012), 75-98.

Gau, C., \& Viskanta, R., Effect of natural convection on solidification from above and melting from below of a pure metal. International Journal of Heat Mass Transfer, 28, (1985), 573-587.

Gau, C., \& Viskanta, R., Melting and solidification of a pure metal on a vertical wall. Journal of Heat Transfer, 108, (1986), 174-181.

Christiano, G. S. S., \& Luiz, F.M., Numerical study of melting of tin within a rectangular cavity including convective effects, Proceeding of COBEM 2011, Brazilian Congress of Mechanical Engineering, Natal, RN, Brazil. 
Gu, Z., Liu, H., \& Li, Y., Thermal energy recovery of air conditioning system--heat recovery system calculation and phase change materials development. Applied Thermal Engineering, 24(17), (2004), 2511-2526.

Ho, C. J., \& Viskanta, R. Heat transfer during melting from an isothermal vertical wall. Journal of Heat Transfer, 106, (1984), 12-19.

Joulin, A., Younsi, Z., Zalewski, L., Lassue, S., Rousse, D. R., Cavrot, J. P., Experimental and numerical investigation of a phase change material: Thermalenergy storage and release, Applied Energy 88, (2011), 2454-2462

Kamkari, B., \& Shokouhmand, H., Experimental investigation of phase change material melting in rectangular enclosures with horizontal partial fins. International Journal of Heat and Mass Transfer, 78, (2014), 839-851.

Kamkari, B., Shokouhmand, H., F. Bruno, F., Experimental investigation of the effect of inclination angle on convection-driven melting of phase change material in a rectangular enclosure, Int. J. Heat Mass Transf. 72, (2014), 186-200.

Kenisarin, M. M., High-temperature phase change materials for thermal energy storage. Renewable and Sustainable Energy Reviews. 14(3), (2010), 955-970.

Khalifa, A. J. N., Suffer, K. H., \& Mahmoud, M. S., A storage domestic solar hot water system with a back layer of phase change material. Experimental Thermal and Fluid Science, 44, (2013), 174-181.

Khodadadi, J. M., \& Hosseinizadeh, S. F., Nanoparticle-enhanced phase change materials (NEPCM) with great potential for improved thermal energy storage. International Communications in Heat and Mass Transfer, 34(5), (2007), 534-543.

Kim, T. Y., Hyun, B., Lee, J., \& Rhee, J., Numerical study of the spacecraft thermal control hardware combining solid-liquid phase change material and a heat pipe. Aerospace Science and Technology, 27(1), (2013),10-16.

Liu, M., Saman, W., \& Bruno, F., Development of a novel refrigeration system for refrigerated trucks incorporating phase change material. Applied Energy, 92, (2012), 336-342.

Niemela, J. J., Skrbek, L., Sreenivasan, K. R., and Donnelly, R. J. Turbulent convection at very high Rayleigh numbers, Nature, 404, (2000), 837-840.

Ravikumar, M., \& Srinivason, D. P., PHASE CHANGE MATERIAL AS A THERMAL ENERGY STORAGE MATERIAL FOR COOLING OF BUILDING. Journal of Theoretical and Applied Information Technology, (2008), 503-511.

Robak, C. W., Bergman, T. L., \& Faghri, A., Enhancement of latent heat energy storage using embedded heat pipes. International Journal of Heat and Mass Transfer, 54(15), (2011), 3476-3484.

Sarier, N., \& Onder, E., Organic phase change materials and their textile applications: An overview. Thermochimica Acta, (2012), 540, 7-60. 
Sharifi, N., Bergman, T. L., \& Faghri, A., Enhancement of PCM melting in enclosures with horizontally-finned internal surfaces. International Journal of Heat and Mass Transfer, 54(19), (2011), 4182-4192.

Sharma, A., Review on thermal energy storage with phase change material and applications. Renewable and Sustainable Energy Reviews, 13, (2009), 318-345

Shokouhmand, H., \& Kamkari, B., Experimental investigation on melting heat transfer characteristics of lauric acid in a rectangular thermal storage unit. Experimental Thermal and Fluid Science, 50, (2013), 201-222.

Stritih, U., \& Butala, V., Experimental investigation of energy saving in buildings with PCM cold storage. International Journal of Refrigeration, 33(8), (2010), 1676-1683.

Swanson, T. D., \& Birur, G. C., NASA thermal control technologies for robotic spacecraft. Applied Thermal Engineering, 23(9), (2003), 1055-1065.

Tan, F., \& Tso, C., Cooling of mobile electronic devices using phase change materials. Applied Thermal Engineering, 24(2-3), (2004), 159-169.

Tay, N. H. S., Belusko, M., \& Bruno, F., Designing a PCM storage system using the effectiveness-number of transfer units method in low energy cooling of buildings. Energy and Buildings, 50, (2012), 234-242.

Tay, N. H. S., Bruno, F., \& Belusko, M., Comparison of pinned and finned tubes in a phase change thermal energy storage system using CFD. Applied Energy, 104, (2013), 79-86.

Tumuluri, K., Alvarado, J. L., Taherian, H., \& Marsh, C., Thermal performance of a novel heat transfer fluid containing multiwalled carbon nanotubes and microencapsulated phase change materials. International Journal of Heat and Mass Transfer, 54(25), (2011), 5554-5567.

Velraj, R., Seeniraj, R. V., Hafner, B., Faber, C., \& Schwarzer, K., Heat transfer enhancement in a latent heat storage system. Solar Energy, 65(3), (1999), 171-180.

Wang, J., Xie, H., Xin, Z., Li, Y., \& Chen, L., Enhancing thermal conductivity of palmitic acid based phase change materials with carbon nanotubes as fillers. Solar Energy, 84(2), (2010), 339-344.

Wang, Y., Amiri, A., \& Vafai, K., An experimental investigation of the melting process in a rectangular enclosure. International Journal of Heat and Mass Transfer, 42(19), (1999), 3659-3672.

Webb, B. W., \& Viskanta, R. Natural convection dominated melting heat transfer in an inclined rectangular enclosure. International Journal of Heat Mass Transfer, 29, (1986), 183-192.

Wolff, F., \& Viskanta, R. Solidification of a pure metal at a vertical wall in the prsence of liquid superheat. International Journal of Heat and Mass Transfer, 31, (1988), 1735-1744. 
Yanxia, D., Yanping, Y., Daiyong, J., Baoyi, C., Jinfeng, M., Experimental investigation on melting characteristics of ethanolamine-water binary mixture used as PCM, International Communications in Heat and Mass Transfer 34, (2007), 10561063

Yunus, C. \& Turner, R., Fundamentals of Thermal-Fluid Sciences, 1st ed., McGrawHill, New York, NY 10020, USA ISBN 0-07-239054-9, (2001). 